Review

\title{
A Comprehensive Review of Lithium-Ion Cell Temperature Estimation Techniques Applicable to Health-Conscious Fast Charging and Smart Battery Management Systems
}

\author{
Akash Samanta ${ }^{1, *(\mathbb{D})}$ and Sheldon S. Williamson ${ }^{2}$ \\ 1 Department of Applied Physics, Faculty of Electrical Engineering, University of Calcutta, \\ Kolkata 700009, India \\ 2 Department of Electrical, Computer and Software Engineering, Faculty of Engineering and Applied Science, \\ Ontario Tech University, Oshawa, ON L1G 0C5, Canada; Sheldon.Williamson@ontariotechu.ca \\ * Correspondence: akashsamanta440@gmail.com; Tel.: +91-9143877405
}

check for updates

Citation: Samanta, A.; Williamson, S.S. A Comprehensive Review of Lithium-Ion Cell Temperature Estimation Techniques Applicable to Health-Conscious Fast Charging and Smart Battery Management Systems. Energies 2021, 14, 5960. https:// doi.org/10.3390/en14185960

Academic Editors: Andrei Blinov, Sheldon Williamson, Seung-Wan Song and Mario Marchesoni

Received: 5 July 2021

Accepted: 13 September 2021

Published: 20 September 2021

Publisher's Note: MDPI stays neutral with regard to jurisdictional claims in published maps and institutional affiliations.

Copyright: (c) 2021 by the authors. Licensee MDPI, Basel, Switzerland. This article is an open access article distributed under the terms and conditions of the Creative Commons Attribution (CC BY) license (https:// creativecommons.org/licenses/by/ $4.0 /)$.

\begin{abstract}
Highly nonlinear characteristics of lithium-ion batteries (LIBs) are significantly influenced by the external and internal temperature of the LIB cell. Moreover, a cell temperature beyond the manufacturer's specified safe operating limit could lead to thermal runaway and even fire hazards and safety concerns to operating personnel. Therefore, accurate information of cell internal and surface temperature of LIB is highly crucial for effective thermal management and proper operation of a battery management system (BMS). Accurate temperature information is also essential to BMS for the accurate estimation of various important states of LIB, such as state of charge, state of health and so on. High-capacity LIB packs, used in electric vehicles and grid-tied stationary energy storage system essentially consist of thousands of individual LIB cells. Therefore, installing a physical sensor at each cell, especially at the cell core, is not practically feasible from the solution cost, space and weight point of view. A solution is to develop a suitable estimation strategy which led scholars to propose different temperature estimation schemes aiming to establish a balance among accuracy, adaptability, modelling complexity and computational cost. This article presented an exhaustive review of these estimation strategies covering recent developments, current issues, major challenges, and future research recommendations. The prime intention is to provide a detailed guideline to researchers and industries towards developing a highly accurate, intelligent, adaptive, easy-to-implement and computationally efficient online temperature estimation strategy applicable to health-conscious fast charging and smart onboard BMS.
\end{abstract}

Keywords: electric vehicles; machine learning; Kalman filter; thermal modelling; online prediction; electromagnetic impedance spectroscopy; computational cost

\section{Introduction}

Lithium-ion batteries (LIBs) are widely used in electric vehicles (EVs), grid-tied stationary energy storage systems, and several other consumer electronics primarily due to their high voltage rating (>4 V/cell) and high energy density ( 265 (W h) $\left.\mathrm{L}^{-1}\right)$ and longer operational life. The use of LIBs in automotive and aerospace applications has led to larger cell sizes and large battery packs for a higher driving range and the requirement for more aggressive charging and discharging. However, thermal instability and temperaturedependent nonlinear behavior is some of the common concerns behind the safe and reliable operation of LIB systems. It is noticed that the operation of batteries outside the safe operating temperature directly affects the performance of LIBs, such as cycle life, efficiency, reliability and safety. Researchers investigating the thermal performance of LIB showed that the best operating temperature range is from $25^{\circ} \mathrm{C}$ to $40^{\circ} \mathrm{C}$ [1,2]. Richardson et al. [3] demonstrated that the difference between the core and surface temperature could reach more than $10^{\circ} \mathrm{C}$ during real-life applications, especially during the high discharging condi- 
tion and fluctuating load current demand. The excessive temperature difference and the accumulation of a large amount of heat inside the cell could lead to thermal runaway or even explosions and fire [4]. That necessitates the employment of a battery management system (BMS) for effective monitoring of battery parameters (current, voltage, temperature), estimation of battery states (state of charge (SOC), state of health $(\mathrm{SOH})$, remaining useful life (RUL), state of temperature (SOT) [5]). Research studies demonstrated that SOC [6], $\mathrm{SOH}$ [7], and remaining storage capacity [8] are a function of temperature; thus, the estimation of the battery states also depends on the accurate estimation of cell temperature. The Columbic efficiency of a cell is greatly affected by the cell temperature during the charging and discharging period. Few other popular functionalities of BMS include cell balancing [9] and fault detection/diagnosis [10] to ensure optimum capacity utilization, operational safety, reliability, and longer battery life often requires temperature information of an individual cell and battery pack as well. Therefore, accurate information of core and surface temperature is highly crucial for effective thermal management and safety of a LIB pack. Moreover, in cold climate areas, the battery capacity is drastically reduced due to low-temperature operation that requires preheating the battery to a suitable range for optimum performance [11,12]. It is also evidenced that for every $0.1{ }^{\circ} \mathrm{C}$ beyond the safe operating region the battery capacity degrades by about $5 \%$ [13]. It is evidenced that maximum heat is generated during the discharging period especially with fast discharging [14]. Therefore, accurate temperature estimation is essential for effective thermal management and safety during fast charging and discharging and preheating of the cell to minimize capacity fade.

In summary, it could be stated that the accurate information of cell temperature is undoubtedly serving as the essential basis for the thermal management and safety of LIB. While the surface temperature of each cell can be measured by installing a temperature sensor on each cell, the core or internal temperature measurement directly using physical sensors is challenging. Moreover, installing a temperature sensor on each cell surface is not practically feasible from a system cost, space and weight point of view as any high-capacity battery pack used in EVs and grid-tied systems essentially consists of thousands of individual cells. Researchers have also incorporated multi-dimensional sensing and self-healing functions into a single battery cell to develop a smart battery [15-18]. Smart cells are typically capable of parameter measurements and estimation of cell states including the state of temperature. Despite the modularized application of BMS in smart batteries, accurate temperature estimation is still required, as otherwise installing sensors in each cell results in high implementation cost and complexity. Therefore, researchers are struggling hard to develop a high-fidelity, accurate, easy-to-implement, and computationally inexpensive online temperature estimation strategy suitable for low-cost onboard BMS. Several temperature estimation techniques have been proposed by researchers so far. Each different type of method has its advantages and limitations with respect to the above-mentioned features of an optimum BMS. Therefore, a summary of all the prominent techniques would be very helpful to researchers and developers serving as a baseline for further research and as a guideline for selecting appropriate techniques suitable for a specific requirement. However, such a summary with detailed discussion on current progress and explanation of the existing issues, challenges and future research scopes has not yet been presented in the literature. Therefore, this article covered the research gap by conducting a comprehensive review of the state-of-the-art temperature estimation strategies reported in the literature so far.

The paper is organized as follows: In Section 2, generic temperature estimation strategy of LIB is presented. The classification of temperature estimation strategies is presented in Section 3. Section 4 is dedicated to presenting the existing estimation techniques, their evolutions, limitations and challenges. It should be noted that temperature estimation strategies for LIBs reported in the literature between 2010 to 2021 are primarily considered. However, few prominent research articles published between 1990 to 2010 are also considered for understanding the fundamentals and evolution of temperature estimation 
schemes. Commonly used search platforms, such as "Google Scholar", "Science Direct", and IEEE Xplore, were used to find research articles published within this tenure. The search criteria were "Temperature Estimation of Lithium-ion Batteries". Section 5 discusses the current issues, challenges and future research recommendations. Finally, Section 6 is dedicated to a summary of the major findings and concluding remarks.

\section{Generic Temperature Estimation Strategy}

Irrespective of battery chemistry, heat is accumulated inside the battery during the charging/discharging even during idle conditions, majorly due to several largely exothermic chemical and electrochemical reactions as well as transport processes. If the heat transfer from the battery to the surroundings is not sufficient, then the heat gets accumulated inside the battery resulting in an increase in core and surface temperature, thereby risking thermal runaway. This phenomenon is even more prominent in the case of hard-cased insulated batteries (as used in EVs), under fast charging/discharging and the operation in hot environments. Heat dissipation is worse in cylindrical LIBs that are extensively used in high-capacity LIB packs. Therefore, a typical temperature estimation scheme consists of two models, namely, a heat generation model and a heat transfer model [19]. Often, a battery electrical model is also used to estimate the total heat generation using Bernardi's [20] heat generation model whereas few other models use a mathematical form of battery electrochemistry to calculate the heat generation. Adaptive estimation strategies also consider the influence of different battery states, such as $\mathrm{SOC}$ and $\mathrm{SOH}$, as the battery temperature is a function of these battery states. Then, the heat transfer model takes the estimated total heat quantity as well as few other external measurements such as ambient temperature to predict the temperature of that cell. Closed-loop estimation schemes use the measured or the estimation temperature as feedback to improve the prediction accuracy. A schematic layout of a generic temperature estimation strategy for LIB is shown in Figure 1.

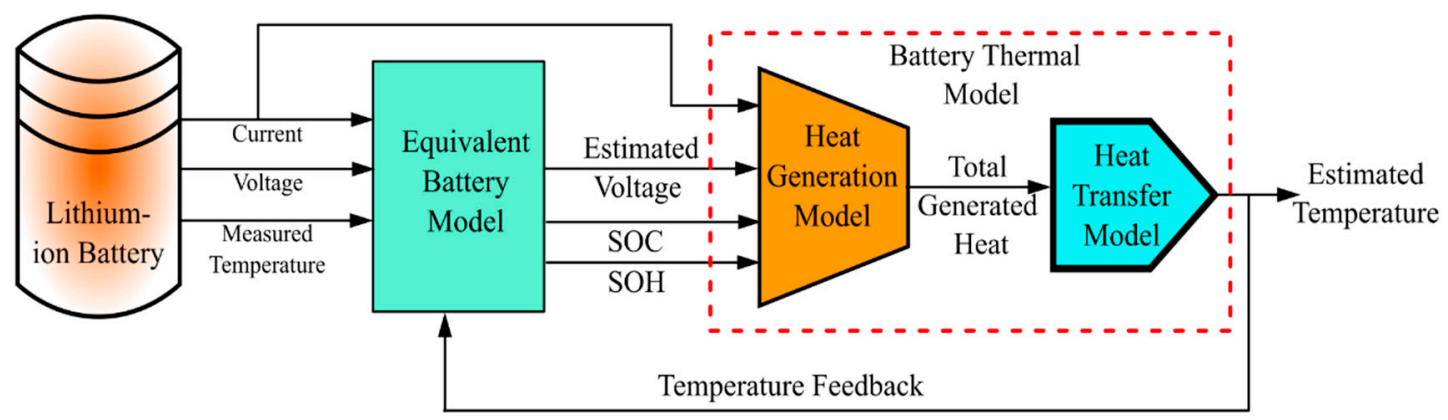

Figure 1. Schematic layout of a generic temperature estimation strategy for a LIB cell.

\section{Classification of Temperature Estimation Strategies}

As shown in Figure 1, typically, a temperature estimation scheme consists of a heat generation model and a heat transfer model. The heat generation models reported in the literature can be broadly classified from two different aspects; based on modelling strategy and based on the source of heat generation. Heat generation models based on modelling strategy can be classified into three groups, physics-based electrochemical models [21-24], equivalent circuit models (ECM) [25-27], black-box models [28-30]. In contrast, based on the source of heat generation, these models can be grouped as a concentrated model, distributed model [31] and heterogeneous model [25,32]. The concentrated heat generation model considers that all heat is generated at the core only, usually considered to reduce the modelling complexity. The distributed heat generation model considers that uniform heat is generated throughout the entire cell geometry whereas the heterogeneous model can capture different heat generation from difference cell layers usually resulting in temperature and current density gradients inside the cell. The heterogeneous models are more detailed thus can produce highly accurate predictions; however, these are most complex and require 
extensive experiments for modelling. Distributed heat generation models are a balance between the concentrated and heterogeneous models. The heat transfer models can be classified into finite element analysis (FEA)-based models [27,33-36], heat capacitor-resistor models (lumped or distributed parameter) [28,37-40], and data-driven techniques. Heat capacitor-resistor-based models use the analogy between electrical and thermal systems. A heat capacitor-resistor can be further classified as mentioned in Figure 2. Lumped parameter models are simple and useful for online applications, however, only one or two average temperatures can be predicted with these models whilst the battery temperature distribution is not spatially uniform, especially in larger capacity cylindrical LIB cells. On the other hand, complex distributed models [41,42] can describe the detailed temperature distribution in a cell, however, they are not suitable for online application due to their computational complexity. Several other detailed models of LIB accounting for the thermal characteristics of different layers are studied in [43-48]. A two-state/node model provides information on core and surface temperature whereas a one-state/node model can provide only core temperature.
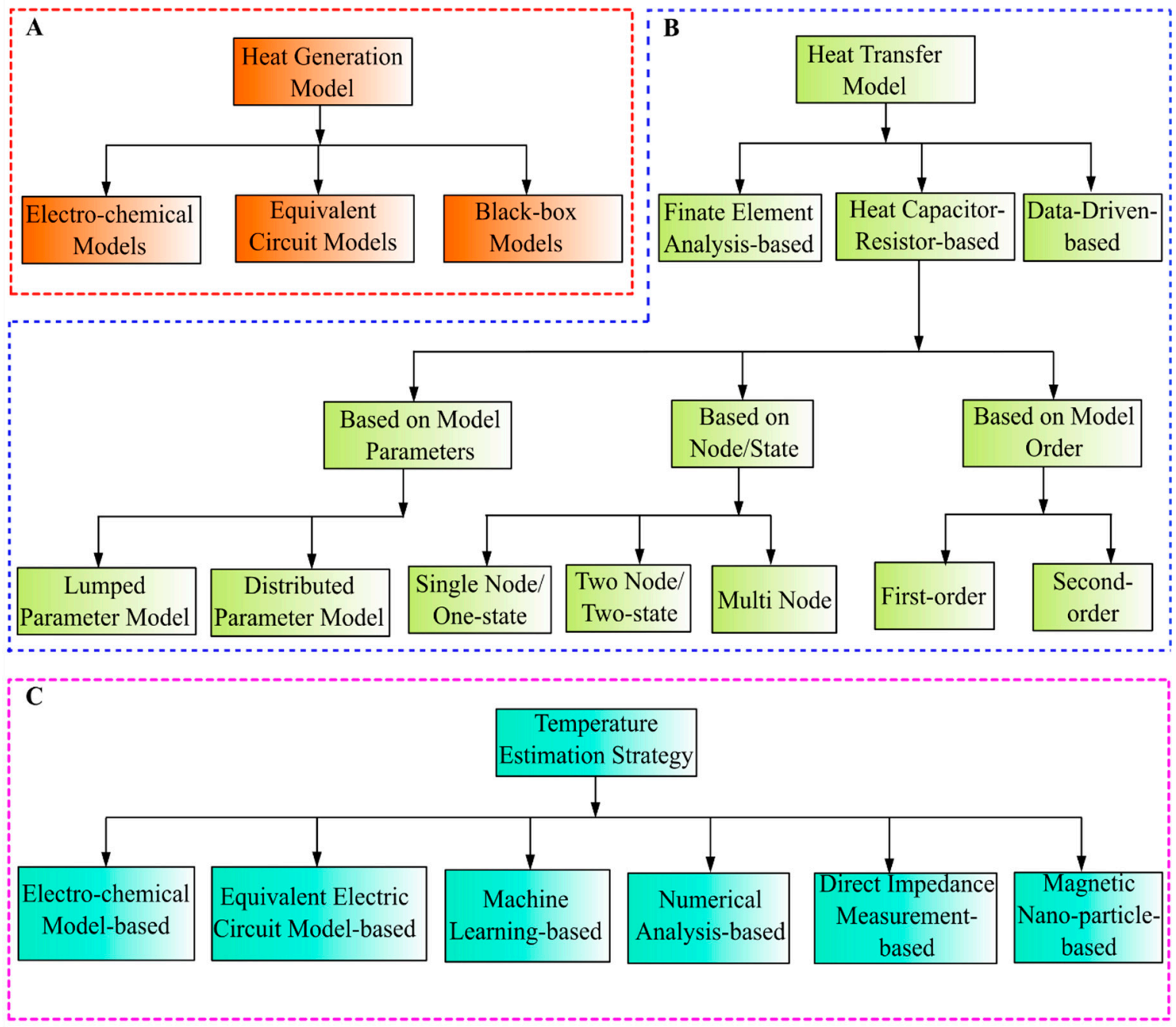

Figure 2. Family of (A) Heat generation model, (B) Heat transfer model, (C) Temperature estimation strategy.

The heat transfer model where the total heat generation is one of the input parameters is collectively called the battery thermal model where the total heat generation is estimated by the battery heat generation model. The thermal modelling of LIB is a separate area of study and is not under the scope of this study. It deals only with the temperature estimation strategies. However, as most of the temperature estimation strategies are 
extensively depending on thermal modelling, an overview of each modelling technique is also discussed with the respective temperature estimation strategy for better understanding. Researchers employed different types of heat generation models with different kinds of heat transfer models to come up with a temperature estimation scheme. Therefore, it is challenging to classify these estimation strategies. Broadly, the temperature estimation schemes can be grouped into electrochemical thermal modelling-based, equivalent electric circuit model (EECM)-based, machine learning (ML)-based, numerical-model based, direct impedance measurement-based, magnetic nanoparticles-based schemes. The families of the LIB heat generation model, heat transfer model and temperature estimation strategy are illustrated in Figure 2.

\section{Comprehensive Review of Temperature Estimation Strategies}

\subsection{Electrochemical Thermal Modelling-Based Temperature Estimation}

Researchers started thermal modelling in the early nineties, those are mostly coupled with an electrochemical model to simulate the temperature profile of a battery under different operating conditions, geometries or cooling rates. There are simple one-dimensional (radial direction) models [37,49-54] to complex three-dimensional thermal models [55-59]. Researchers have primarily used different analytical techniques to mathematically model the electrochemical behavior of the cell. One-dimensional models typically assume isothermal, constant current operation of the battery and lumped thermophysical properties and constant heat generation rates. Highly complex three-dimensional models require an in-depth understanding of the thermodynamic properties of battery materials and parts to consider the heat effects caused by ohmic resistance, chemical reactions, mixing processes, polarization and electrode kinetic resistance. Often, temperature estimation using such highly complex models is very accurate, however, such detailed models are essential for battery design purposes. Those are not compatible with temperature estimation using onboard BMS with low computational resources. These complex models are capable of accounting for the time-varying nonlinear battery performance. However, they typically require several system properties, operational parameters which require extensive experimental measurements. While, at the same time, quantitative estimation of some of the properties, such as transport properties, thermodynamic properties and heat effects are highly challenging.

Thomas and Newman [60] introduced an electrochemical modelling-based detailed heat generation model of LIB to estimate the total heat generation during the charging/discharging period. The fundamental equation of the total heat generation inside the LIB cell as proposed by Thomas and Newman reads

$$
Q=I\left(V-U^{a v g}\right)+I T \frac{\partial U^{a v g}}{\partial T}-\sum_{i} \Delta H_{i}^{a v g} r_{i}-\int \sum_{j}\left(\bar{H}_{j}-\bar{H}_{j}^{a v g}\right) \frac{\partial C_{j}}{\partial t} d v
$$

In Equation (1), $Q$ is the rate of heat generated or consumed inside the cell, $V$ and $U$ are the cell voltage and equilibrium potential, respectively, $I$ is the charging or discharging current, $T$ is the cell temperature. $\Delta H_{i}$ represents the changes in enthalpy of the chemical reaction $i$ and $r_{i}$ is the rate of reaction i. $\Delta \bar{H}_{j}$ represents the partial molar enthalpy of species $\mathrm{j}$ and $c_{j}$ is the concentration of the species. $t$ and $v$ represent the time and volume of the cell, respectively. All the properties are mentioned based on the volume-averaged concentration, thus the superscript " $a v g$ " is used. The model can provide accurate information on heat generation only, temperature estimation is not presented in this study. Their heat generation model was extensively used by several other researchers. Modelling is very detailed thus highly complicated and not suitable for online application owing to the computational burden. One of the widely-used electrochemical models commonly known as the Doyle-Fuller-Newmann model $[37,61]$ is extensively referred to and also used for thermal modelling. It consists of nonlinear partial differential-algebraic equations to describe the internal characteristics of LIB. It is also referred to as the pseudo-twodimensional (P2D) model. The major limitation of the model is its high computational 
burden which limits its application in online state estimation in embedded BMSs. Here, Al Hallaj et al. [53] showed that a simplified transient one-dimensional thermal model with lumped parameters is sufficient for cell design purposes, especially to simulate the thermal behavior of scaled-up LIBs. Detailed knowledge of the role of different cell components, such as electrodes, electrolytes and separators in heat generation is also not necessary. Few researchers used this type of complex electrochemical model to explore pulse power limitations to prevent thermal runaway and to design thermal management systems [62,63]. Those are mostly used for designing LIB cells as well as LIB packs. A lumped electrochemical-thermal-coupled model was used to predict the thermal performance of LIB alongside the performance of individual electrodes at various operating temperatures by Fang et al. [64]. The model was validated against the experimental data for constant current and pulsing conditions characteristic of hybrid electric vehicle (HEV) which are merely providing the laboratory experimental results instead of a real-work application scenario. The impact of charging current on internal temperature behavior was investigated in [65]. Gerver et al. [66] included more detailed information and cell characteristics to develop a multi-dimensional electrochemical thermal model of LIB to analyze the thermal performance and heat generation more accurately. Despite estimation accuracy, the modelling complexity and computational burden limit its application in embedded BMS.

Due to a lack of clear understanding of the electrochemical processes inside the LIB and their corresponding mathematical equations alongside to reduce the computational expenses, often all heat generation sources were not modelled/considered. These unmodeled heat generation behaviors lead to significant errors in temperature estimation. Regarding this, Zhang et al. [67] developed a two-state thermal model utilizing discretization and inverse model techniques which do not require prior knowledge of thermal boundary conditions. Moreover, the model is capable of estimating the total heat generation of a battery cell, thus, thermal modelling of each heat source is not required and abnormal heat generation can also be detected from the estimation results. The effectiveness and robustness of the model were tested for varying thermal boundary conditions and fast charging conditions. While the strategy is designed for self-heating pouch cells, a similar approach could also be adapted for other types of LIBs. Thus, further research is recommended here. A high-fidelity electrochemical model and onboard measurements such as terminal voltage and current were used by Wang et al. [68] to estimate the cell temperature at a wide range of C-rates during the charging/discharging period. They have also used a dual ensemble Kalman filter (DEKF) which incorporates enhanced singleparticle dynamics to relate terminal voltage to battery temperature and $\mathrm{Li}+$ concentration. Besides, modelling complexity and high computational cost, the accurate determination of lithium $(\mathrm{Li}+)$ concentration is challenging. Therefore, the application of the model in real-life online prediction is questionable. The spatial distribution of internal temperature in LIB was estimated using a pseudo-2D electrochemical model and soft-constrained dual unscented Kalman filter (DUKF) by Marelli and Corno [69]. It is mainly developed to estimate the $\mathrm{Li}+$ concentration and modelling complexity and computational expenses are very high. However, the approach could be extended for temperature estimation. Smith et al. [62] developed a one-dimensional electrochemical, lumped thermal model to explore pulse power limitations and thermal behavior of a LIB pack. The electrochemical thermal modelling-based temperature estimation strategies proposed by different authors are summarized in Table 1 for a quick reference to the readers. In general, the major limitations of any electrochemical model-based strategies are the modelling complexity and high computational cost making these models unsuitable for online prediction and application at low-cost onboard BMS. 
Table 1. Summary of electrochemical thermal modelling-based temperature estimation strategies.

\begin{tabular}{|c|c|c|}
\hline Reference & Types of Models & Important Note \\
\hline Thomas and Newman [60] & $\begin{array}{l}\text { One-dimensional } \\
\text { electrochemical model }\end{array}$ & Not used for temperature estimation \\
\hline $\begin{array}{l}\text { Doyle-Fuller-Newmann model } \\
\qquad[37,61]\end{array}$ & $\begin{array}{l}\text { Pseudo-two-dimensional } \\
\text { (P2D) model }\end{array}$ & $\begin{array}{c}\text { Not used for temperature estimation but several other } \\
\text { researchers used }\end{array}$ \\
\hline Al Hallaj et al. [53] & $\begin{array}{l}\text { A transient one-dimensional } \\
\text { thermal model with } \\
\text { lumped parameters }\end{array}$ & $\begin{array}{l}\text { Detailed information of electrodes, electrolytes and } \\
\text { separator were considered in heat generation model }\end{array}$ \\
\hline Fang et al. [64]. & $\begin{array}{l}\text { Lumped parameter } \\
\text { electrochemical-thermal- } \\
\text { coupled model }\end{array}$ & $\begin{array}{l}\text { Can estimate one or two average temperatures, } \\
\text { performance of individual electrode at various operating } \\
\text { temperatures, constant current and pulsing conditions } \\
\text { characteristic were considered, experimentally validated }\end{array}$ \\
\hline Gu and Wang [41] & $\begin{array}{l}\text { Thermal energy generation model, } \\
\text { multiphase micro-macroscopic } \\
\text { electrochemical model }\end{array}$ & $\begin{array}{l}\text { Temperature-dependent physicochemical properties and } \\
\text { thermal behaviors under various charging conditions } \\
\text { were considered. Capable of predicting the average cell } \\
\text { temperature as well as the temperature distribution inside } \\
\text { a cell, volume-averaging technique, numerical simulations }\end{array}$ \\
\hline Kumaresan et al. [42] & One-dimensional thermal model & $\begin{array}{c}\text { Thermal dependence of various parameters in the model } \\
\text { on different discharge profiles was assessed, validated } \\
\text { using experimental and simulation results }\end{array}$ \\
\hline Kim et al. [65] & $\begin{array}{l}\text { Two-dimensional modelling + } \\
\text { Finite element method (FEM) }\end{array}$ & $\begin{array}{l}\text { Able to provide temperature distribution based on } \\
\text { potential and current density distribution, MATLAB, } \\
\text { validated using experimental and simulation results }\end{array}$ \\
\hline Gerver et al. [66] & $\begin{array}{l}\text { A multi-dimensional } \\
\text { electrochemical thermal model }\end{array}$ & $\begin{array}{l}\text { Thermal properties of each cell layer are considered, } \\
\text { experimentally validated }\end{array}$ \\
\hline Wang et al. [68] & $\begin{array}{l}\text { High-fidelity electrochemical } \\
\text { model + onboard measurements + } \\
\text { dual ensemble Kalman } \\
\text { filter (DEKF) }\end{array}$ & $\begin{array}{l}\text { Wide range of C-rates during the charging/discharging } \\
\text { period, MATLAB, validated using experimental and } \\
\text { simulation results }\end{array}$ \\
\hline Marelli and Corno [69] & $\begin{array}{l}\text { Pseudo-2D electrochemical model } \\
\text { and soft-constrained dual } \\
\text { unscented Kalman filter (DUKF) }\end{array}$ & $\begin{array}{l}\text { Can provide information on the spatial distribution of } \\
\text { internal temperature, MATLAB Simulation }\end{array}$ \\
\hline Smith et al. [62] & $\begin{array}{l}\text { A one-dimensional } \\
\text { electrochemical lumped } \\
\text { thermal model }\end{array}$ & $\begin{array}{c}\text { Adaptive to different drive-cycles, tested and validated } \\
\text { with FUDS and HWFET drive cycles, } \\
\text { experimentally validated }\end{array}$ \\
\hline
\end{tabular}

\subsection{Equivalent Electric Circuit Model-Based Temperature Estimation}

An equivalent electric circuit model (EECM) represents the thermal dynamics of LIB using electrical system parameters to develop a heat capacitor-resistor-based battery thermal model. Depending on the number of heat capacitors (number of energy storage elements) two types of models, namely, the first-order model and second-order model have been developed so far in the literature. The first-order model consists of one thermal energy storage element whereas a second-order thermal model consists of two heat capacitors, typically, one for the heat capacitance of the core and the other one is for the cell surface [13]. The second-order model can capture more dynamics than the first-order model. The firstorder and second-order thermal models of a LIB cell are shown in Figure 3a,b, respectively. In Figure $3, Q$ represents the heat generation rate, $C_{c}$ and $C_{s}$ are the heat capacitance of core and surface, respectively, $T_{\text {in }}$ and $T_{\text {out }}$ are the temperatures of core and surface of the cell, respectively. $T_{a m b}$ is the ambient temperature. 


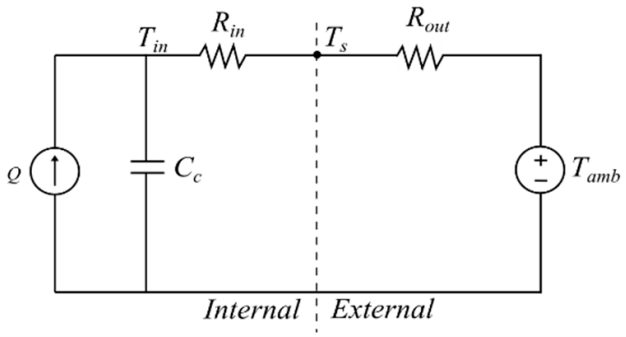

(a)

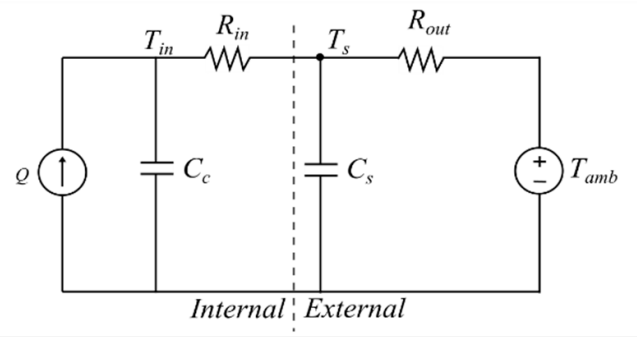

(b)

Figure 3. Thermal model of a LIB cell (a) First-order model, (b) Second-order model.

Further, depending on the modelling complexity, EECM could be also classified as lumped-parameter and distributed parameter models. Lumped-parameter models are used for simplification and thus low computational cost compared to detailed distributed models. Computationally efficient lumped thermal models are developed using single temperature as input to capture the model parameters [70] while some researchers used both surface and core temperatures of the cell to construct the lumped thermal models. Some also considered the correlation between cell geometry and other physical properties with thermal modelling [71]. However, several assumptions were made during modelling leading to inaccurate temperature estimation compared to detailed thermal modelling. Further, thermal models that only estimate the core temperature are considered as singlestate/node [72], whereas if the model can estimate both surface and core temperature then it is termed as two-state/node [67] thermal model. The parameters of the EECM are identified through ranges of experimental studies such as electrochemical impedance spectroscopy (EIS) or utilizing externally measurable quantities, such as voltage, current, and temperature. Few studies also considered various conditions of SOC, SOH and estimated surface/core temperatures to make the model more robust. It is very difficult to group those thermal models because lumped models are used in both single-state and dual-state modelling and the model could be first-order and second-order. Therefore, the literature is grouped into cell-level and pack-level temperature estimation schemes that are discussed below.

Typically, these EECM models determine the value of $Q$ using Equation (2) as formulated by Bernardi et al. [20]:

$$
Q=I\left(V-V_{O C V}\right)+I T_{c} \frac{d V_{o c v}}{d T_{c}}
$$

where $V_{o c v}$ represents the open-circuit voltage of the battery cell and the term $\frac{d V_{o c v}}{d T_{\mathcal{C}}}$ is the entropy coefficient. Finally, $T_{c}$ and $T_{S}$ are estimated using the mathematical form of the thermal models shown in Figure 3. Mathematical equations for temperature estimation using the firstorder and second-order thermal model are represented by Equations (3) and (4), respectively.

\subsubsection{EECM-Based Cell Temperature Estimation}

One of the prime challenges of any EECM-based strategy is model parameter identification. Forgeze et al. [43] used transient experiments by applying current pulses of different magnitudes to increase the internal temperature and the model parameters, heat transfer coefficients and heat capacity were determined to construct a lumped parameter thermal model. This study used EIS for parameter identification where current pulses at $2 \mathrm{~Hz}$ were used to increase the internal temperature. The $T_{\mathcal{C}}$ was estimated based on the measured surface temperature using the lumped parameter thermal model. The entropy change was also taken into account while modelling. They developed a first-order thermal 
model as shown in Figure 3a. The mathematical representation of the first-order thermal model as used by Forgeze et al. reads

$$
T_{\text {in }}=T_{s}\left(1+\frac{R_{\text {in }}}{R_{\text {out }}}\right)-T_{\text {amb }} \frac{R_{\text {in }}}{R_{\text {out }}}
$$

The strategy developed by Forgez et al. lacks quantitative analysis of the influence of heat generation. The operating current is much higher compared to the very low current value used in EIS. Therefore, model parameters determined using EIS are not appropriate for capturing the thermal dynamics accurately. Moreover, they have considered uniform internal temperature, however, more than $10^{\circ} \mathrm{C}$ temperature difference among different internal points of a cell has been reported in the same study. This strategy requires surface temperature measurement by installing a temperature sensor at each cell, thus scaling-up is impractical. Maleki and Shamsuri [73] developed a thermal model of notebook computer LIB-pack to understand the thermal response under various operating conditions aiming to reduce the battery pack designing cost and time. They revealed that the temperature rise during charging is dominated by heat dissipation from the control power electronics while during discharging it is dominated by the heat generated inside the LIB cell. These relevant observations must be considered while designing an effective thermal management system of LIB pack, especially for health-conscious fast charging. Surya et al. [13] developed a second-order thermal model for core and surface temperature estimation scheme using KF. Here, the least square (LS) algorithm was employed to identify the battery thermal parameters. Despite the simplicity and good accuracy, environmental uncertainties were not considered during modelling. Moreover, they presented the results based on simulation study alongside very simple and low-current discharge profile was used for model validation, thus, the accuracy in the real-world applications needs further investigation. Previously, models were validated using a simple charging/discharging current profile. However, the load profile in real-life applications much deviates from those simple loading profiles. Therefore, a second-order thermal model and ECM-based two-state thermal model of cylindrical LIB cell were validated with two basic drive-cycle tests, covering an SOC range $25-100 \%$, temperature $5-38{ }^{\circ} \mathrm{C}$, and maximum C-rate of 22 by Lin et al. [74]. The influence of the constantly varying temperature and SOC on the EECM parameters and consequential effect on battery thermal performance was investigated by Lin et al. [74]. The model demonstrated good prediction accuracy and robustness. However, testing using standard internationally referred drive-cycles was not conducted. Thus, accuracy and robustness in practical scenarios need further investigation. EECM parameters are influenced by cell ageing, thus, Li and Yang [75] considered the influences of ageing and heat transfer conditions on thermophysical model parameters. Li and Yang identified the parameters of the extended lumped parameter model online where a forgetting factor recursive least squares (FFRLS) algorithm was employed.

Further to this research, the uncertainties in practical operation were considered by Lin et al. $[45,76]$ alongside the impact of cell ageing during online parameter identification. As an up-gradation, the commonly deployed LS algorithm was augmented with nonuniform forgetting factors to track the time-varying internal parameters making the model adaptive to cell ageing and other uncertainties. In [77], only two lumped models were used to approximate the core and surface temperatures, respectively, which may not be suitable for a large capacity LIB pack due to strong spatiotemporal thermal distribution. While the influence of overpotential entropy changes on battery heat generation was considered, core temperatures estimation of only a single cell was considered. Sun et al. [78] developed a second-order lumped parameter thermal model with the KF technique for core temperature estimation only (single-state). They used an ECM-based heat generation model to mathematically model the accumulation of the total heat generation at the cell core. As an improvement of previous studies, this study considered the influence of entropy changes and overpotential on cell thermal behavior and was quantitively analyzed to develop an online internal temperature estimation strategy. This strategy utilized surface 
and ambient temperature for core temperature estimation during charge and discharge cycles where the KF was used for adaptive estimation by the process of state and time update in real-time. The impact of unmeasurable modelling error, the initialization error and the possible time-varying external thermal resistance on the temperature estimation accuracy were considered by Dai et al. [79]. In that paper, a second-order lumped parameter thermal model, as shown in Figure 3b, was developed for adaptive core temperature estimation based on the KF. Further, joint Kalman filtering (JKF) was used to simultaneously estimate both core temperature and time-varying external thermal resistance online. The mathematical equation employed by Dai et al. for core temperature estimation can be represented as Equation (4):

$$
T_{i n}(s)=\frac{\left(1+\frac{R_{\text {in }}}{R_{\text {out }}}+C_{s} R_{\text {in }} s\right)}{C_{s} C_{c} s^{2}+\left(C_{s}+C_{c}+\frac{R_{i n} C_{c}}{R_{\text {out }}}\right) s+\frac{1}{R_{\text {out }}}} Q(s)
$$

where $s$ is the Laplace operator. Other parameters are the same as mentioned in Figure 3.

The LS algorithm based on the experimental data was also used to determine the lumped parameters of the thermal model. Dai et al. enhanced the modelling accuracy by constructing a separate thermal model for core and battery shell alongside considering the external heat exchange coefficient as time-varying. The authors simply stated that the proposed method computes efficiently, however, no information about computation time, hardware requirement was presented. Several assumptions were also made during modelling, leading to inaccurate estimation in real-life applications.

A trade-off between the detailed and lumped parameter thermal modelling approaches was considered by Doughty et al. [80] and Park et al. [71]. They developed a two-state thermal model that predicts the surface and core temperature of LIB. The novel intention was to provide more information compared to the lumped model while reducing the computational cost. Few researchers also termed the lumped parameter model as a reduced-order model (ROM). Whilst the primary intention is same, that is, to reduce the complex thermal problem into a simplified heat transfer problem characterized by a reduced set of thermal parameters. A combination of lumped parameter two-state thermal model with 2RC (second-order) ECM along with a joint Kalman filter (JKF)-based core and surface temperature estimation strategy was proposed by Chen et al. [72]. The simulation and experimental test were conducted to verify the adaptiveness of the model to constantly varying temperature and SOC and, finally, the prediction accuracy was also assessed. It was also demonstrated that the proposed model has higher prediction accuracy compared to previously discussed EECMs. It was also demonstrated that the model is highly robust against automatic correction for surface thermal resistance.

To provide more detailed information on the temperature distribution in cylindrical LIB, Xie et al. [81] developed a one-dimensional (radial) lumped parameter thermal model with a dual Kalman filter (DKF). As an improvement, this model is capable to provide temperature information at three different points of the battery, compared to only core and surface temperature. Thus, the researchers termed this modelling as a three-node thermal model. In this study, the anisotropy of thermal conductivity was also considered in identifying internal resistance and SOC during the temperature estimation to enhance the prediction accuracy and robustness. The impact of different charging/discharging current conditions was not considered. Moreover, 1-RC ECM-based heat generation model is considered, thus presumably, the accuracy can be further improved with the application of the 2-RC ECM-based heat generation model. Online parameter estimation using a particleswarm algorithm with pulse discharge experiments under different ambient temperatures was employed by Pan et al. [19]. A combination of 2RC ECM and a multi-node heat transfer model based on the battery geometry was employed in the study to obtain a more detailed temperature gradient inside the large prismatic LIB. The research showed that the hybrid model could provide similar results to the finite element method (FEM), however, the computational burden was reduced by around $90 \%$. They also revealed that the cell 
geometry has a strong influence on the cell temperature profile. Despite good accuracy, the effect of cell ageing and the effort of developing pack-level thermal modelling were not considered in this study.

The impact of heat dissipation through radiation from the surface of the cell was introduced in the thermal modelling of LIB by Sun et al. [82]. A lumped thermal model considering the radiation effect was then used for core temperature estimation with the help of an Extended Unscented Kalman Filter (EUKF). The sensor bias was augmented as an extended state to enhance the prediction accuracy and model robustness. While the load profile of residential energy storage was tested, the suitability in commercial vehicle applications was not tested. Further, model parameters were assumed to be constant irrespective of environmental uncertainties which may be in conflict with the facts when the operating conditions will vary significantly. Zhu et al. [83] developed a lumped twostate thermal-electrical model for estimating both the surface and the core temperatures where the thermal impact of the adjacent cell was also considered during modelling. Further, an extended state observer (ESO) with the feedback of the surface temperature was employed to address the model uncertainties and time-variant parameters in the estimation model. This approach is specifically designed for rapid self-heating of self-heating batteries. The concept of model-based virtual thermal sensors (VTS) was introduced by Xiao Y. [84] that combines the tuned thermal model with a KF observer along with an online parameteridentification algorithm for surface and core temperature estimation utilizing a single temperature sensor input. While the strategy is adaptive to environmental uncertainties, it still requires a sensor for feedback; thus, the strategy cannot be termed as completely sensorless. Despite that it minimizes the sensor requirement and enhances the model adaptability, the concept is similar to other lumped parameter EECM-based methods. The effect of fast-discharge on core temperature of LIB was demonstrated by Surya and Mn [14] where a combination of 1-RC ECM, single-state thermal model and KF was used for core temperate estimation. They used a recursive least square (RLS) algorithm to identify model thermal parameters. However, further research is recommended to develop health-conscious BMS suitable for fast charging/discharging.

\subsubsection{EECM-Based Temperature Estimation of LIB Pack}

Most of the research studies covered only the temperature estimation of a single cell. Thermal modelling and temperature estimation of a LIB pack were seldomly reported. A ROM of a LIB pack considering the characteristic of the inner electrical resistance of the battery was used for core temperature estimation by Ma et al. [85]. Here, RLS was used for the thermal parameter identification. In this study, several assumptions were made while establishing ROM of a battery pack such that parameters of each cell are the same and the thermal behavior of each cell row is same. The heat transfer among cells via conduction through tabs and wires were neglected which could give rise to the error in temperature estimation. Thermal modelling of a LIB pack by scaling-up a single cell thermal model was investigated by Ismail et al. [86] using a simulation study. Considerable accuracy has been noticed, however, several assumptions were made to scale up the single-cell model to battery pack models, such as uniform cell characteristics, constant ambient conditions and $100 \%$ efficient discharging process that are far from the real-life scenario. Therefore, the accuracy of the temperature estimation strategy in real-world applications needs to be further explored. Therefore, from the above discussion, it can be stated that the pack-level estimation schemes need significant further research. The EECMbased temperature estimation strategies proposed by different authors are summarized in Table 2 for a quick reference to the readers. One of the major limitations of EECM-based temperature estimation techniques is the requirement of online sensor feedback. This is because the estimation accuracy is completely relying on accuracy of the knowledge of the cell thermal properties, heat generation rates, and thermal boundary conditions represented in terms of electrical parameters that are subjected to change due to cell aging, operating temperature and other practical uncertainties. 
Table 2. Summary of EECM-based temperature estimation strategies.

\begin{tabular}{cc}
\hline Reference & Types of Models \\
\hline Mahamud et al. [70] & $\begin{array}{c}\text { Lumped Parameter heat } \\
\text { capacitance-resistance thermal model }\end{array}$ \\
\hline Forgeze et al. [43] & $\begin{array}{c}\text { Lumped Parameter, Single-State, } \\
\text { First-order model }\end{array}$ \\
\hline Surya et al. [13] & $\begin{array}{c}\text { Lumped Parameter, Two-State, } \\
\text { Second-order model + Kalman Filter (KF) }\end{array}$ \\
\hline Lin et al. [74] & $\begin{array}{c}\text { Lumped Parameter, Two-State, } \\
\text { Second-order model }\end{array}$ \\
\hline Li and Yang [75] & $\begin{array}{c}\text { Extended lumped parameter, Two-state, } \\
\text { Second-order model + Forgetting factor } \\
\text { Recursive Least Square (FFRLS) }\end{array}$ \\
\hline Lin et al. [45,76] & $\begin{array}{c}\text { Lumped parameter, Two-state model + } \\
\text { Least square (LS) algorithm + } \\
\text { Nonuniform forgetting factors (NUFF) }\end{array}$ \\
\hline Lin et al. [77] & $\begin{array}{c}\text { Lumped-parameter model + } \\
\text { Closed-loop observer }\end{array}$ \\
\hline
\end{tabular}

Sun et al. [78] Lumped parameter, Second-order, Single state thermal model $+\mathrm{KF}$

ANSYS (Ansys, Inc., Canonsburg, PA, USA) FLUENT

Simulation, validated using Experimental and simulation results

Entropy changes are considered, experimentally validated

SOC, Surface temperature variation, MATLAB Simulation

High current rate, varying temperature, SOC, experimental validation using electrochemical impedance spectroscopy data

Temperature variation, cell ageing, SOC, Heat transfer modes, ANSYS Multiphysics Simulation, validated using experimental and simulation results

Cell ageing and uncertainties in practical operation, validated using experimental and simulation results

Influence of overpotential entropy changes, validated using a simulation study

Influence of entropy changes and overpotential, surface and ambient temperature variation, charge/discharge current profile, MATLAB simulation and experimental validation

\begin{tabular}{|c|c|c|}
\hline Dai et al. [79] & $\begin{array}{l}\text { Lumped parameter, Second-order, } \\
\text { Two-state model + JKF + LS algorithm }\end{array}$ & $\begin{array}{l}\text { Initialization error and the possible time-varying external } \\
\text { thermal resistance, validated using experimental data }\end{array}$ \\
\hline $\begin{array}{l}\text { Doughty et al. [80] and } \\
\text { Park et al. [71] }\end{array}$ & $\begin{array}{l}\text { Lumped parameter, Two-state model + } \\
\text { Extended KF }\end{array}$ & $\begin{array}{l}\text { Ambient temperature variation, SOC, validated using a } \\
\text { simulation study }\end{array}$ \\
\hline Chen et al. [72] & $\begin{array}{l}\text { Lumped parameter, Two-state thermal } \\
\text { model + Joint KF (JKF) }\end{array}$ & $\begin{array}{l}\text { Constantly varying temperature, SOC, Surface thermal } \\
\text { resistance, experimentally validated }\end{array}$ \\
\hline Pan et al. [19] & $\begin{array}{l}\text { Lumped Parameter, Second-order, } \\
\text { multi-node model }+ \\
\text { particle-swarm algorithm }\end{array}$ & $\begin{array}{l}\text { Battery geometry, charge/discharge profile, Comparison } \\
\text { with an FEA model, experimentally validated }\end{array}$ \\
\hline Xie et al. [81] & $\begin{array}{l}\text { One-dimensional (radial) lumped } \\
\text { parameter, Three node model + Dual } \\
\text { KF (DKF). }\end{array}$ & $\begin{array}{l}\text { Anisotropy of thermal conductivity, SOC, external } \\
\text { temperature, FEM and Computational Fluid Dynamics } \\
\text { (CFD), experimental validation }\end{array}$ \\
\hline Sun et al. [82] & $\begin{array}{l}\text { Lumped parameter, single-state model + } \\
\text { Extended unscented KF (EUKF) }\end{array}$ & $\begin{array}{l}\text { Sensor bias, Considered heat radiation from the surface, } \\
\text { MATLAB simulation and experimental validation }\end{array}$ \\
\hline Zhu et al. [83] & $\begin{array}{l}\text { Lumped parameter, Two-state model + } \\
\text { extended state observer (ESO) }\end{array}$ & $\begin{array}{c}\text { Thermal impact of an adjacent cell, Model uncertainties } \\
\text { and time-variant parameters, MATLAB simulation, } \\
\text { validation and comparison using electrochemical } \\
\text { impedance spectroscopy data }\end{array}$ \\
\hline Surya and Mn [14] & $\begin{array}{c}\text { Lumped parameter, Single-state thermal } \\
\text { model + KF + Recursive Least Square } \\
\text { (RLS) algorithm }\end{array}$ & Effect of fast-discharge, MATLAB Simulation \\
\hline Xiao Y. [84] & $\begin{array}{l}\text { EECM-based virtual thermal sensors } \\
\text { (VTS) }+ \text { KF }\end{array}$ & $\begin{array}{c}\text { Environmental uncertainties were considered, validated } \\
\text { using experimental and simulation results }\end{array}$ \\
\hline $\begin{array}{l}\text { Ma et al. [85] and } \\
\text { Ismail et al. [86] }\end{array}$ & $\begin{array}{c}\text { ROM of a LIB pack for a central } \\
\text { temperature of LIB pack + Recursive least } \\
\text { square (RLS) }\end{array}$ & $\begin{array}{l}\text { Temperature, SOC, validated using experimental and } \\
\text { simulation results }\end{array}$ \\
\hline
\end{tabular}




\subsection{Numerical Analysis-Based Temperature Estimation}

Numerical method-based techniques were successfully implemented for temperature estimation of different chemistries and shapes of LIB cells and even LIB packs. So far, the finite element method (FEM) [87-90] and finite volume method (FVM) [91] were extensively used for temperature estimation. Numerical analysis-based techniques try to mathematically describe the thermal dynamics inside the battery using nonlinear partial differential equations (PDEs) such as used by Du et al. [89]. They have employed FEM analysis with a three-dimensional model and Bernardi equation-based internal heat generation rate. Typically, the PDEs have complex boundary conditions that are infinite-dimensional. The fundamental mathematical equation as employed by Du et al. can be represented as Equation (5)

$$
\rho C_{p} \frac{\partial T}{\partial t}=\lambda_{x} \frac{\partial^{2} T}{\partial x^{2}}+\lambda_{y} \frac{\delta^{2} T}{\delta y^{2}}+\lambda_{z} \frac{\delta^{2} T}{\delta z^{2}}+Q
$$

where $\rho, C_{p}$ represent the mean density and mean specific heat of the cell, respectively. $\lambda$ is the heat conductivity coefficient of the surface material of the cell and $Q$ is the same as in Equation (1).

Dong Hyup Jeon [87] incorporated a transient thermoelectric model with a porous electrode model and conducted a numerical simulation to understand the thermal behavior of a commercial LIB under charging and discharging conditions. He demonstrated that temperature increase during discharging is much higher compared to the temperature rise during charging. He also suggested that the temperature difference between charge and discharge can be decreased with increasing C-rates. Further, Baba et al. [88] conducted a numerical simulation of an enhanced single-particle model of a LIB to understand the three-dimensional temperature distribution inside the cell. Numerical analysis was used for transient behaviors of a LIB under a dynamic driving cycle by Yi et al. [90]. Doublelayer thermal capacitance was used to capture the short-term transient behavior of the LIB chemistry. Fleckenstein et al. [91] using FVM to demonstrate that the temperature gradients inside the cell layer result in different current densities and local SOC inhomogeneities in LIB. These phenomena must be well-taken care of while designing an effective thermal management system. In general, this kind of model is best for capturing both temporally and spatially thermal distribution of the cell as the battery thermal process is a typical distributed parameter system. Despite high accuracy and detailed information about cell temperature gradient, these numerical method-based temperature estimation strategies are not suitable for online temperature estimation due to high computational cost. The complex mathematical analysis also required expertise and strong domain knowledge. Moreover, generalization is not possible as different chemistry and cell physics affect mathematical modelling. A summary of numerical methods-based temperature estimation strategies is shown in Table 3.

Table 3. Summary of numerical methods-based temperature estimation strategies.

\begin{tabular}{ccc}
\hline Reference & Types of Models & Important Note \\
\hline Dong Hyup Jeon [87] & $\begin{array}{c}\text { A transient thermoelectric } \\
\text { model with a porous electrode } \\
\text { model + finite element } \\
\text { method (FEM) }\end{array}$ & $\begin{array}{c}\text { Different driving cycles, COMSOL Multiphysics (COMSOL Inc., } \\
\text { Stockholm, Sweden) simulation and Experimental validation }\end{array}$ \\
\hline Baba et al. [88] & $\begin{array}{c}\text { Enhanced single-particle } \\
\text { model + FEM }\end{array}$ & $\begin{array}{c}\text { Three-dimensional temperature distribution inside the cell, cell } \\
\text { geometry, and current profile, experimentally validated }\end{array}$ \\
\hline Du et al. [89] & $\begin{array}{c}\text { Three-dimensional model + } \\
\text { ECM based heat generation } \\
\text { model + FEM }\end{array}$ & $\begin{array}{c}\text { Different current profiles, temperature variation, COMSOL } \\
\text { Multiphysics simulation and experimental validation }\end{array}$ \\
\hline
\end{tabular}


Table 3. Cont

\begin{tabular}{ccc}
\hline Reference & Types of Models & Important Note \\
\hline Yi et al. [90] & $\begin{array}{c}\text { Transient thermoelectric } \\
\text { model + FEM }\end{array}$ & $\begin{array}{c}\text { Transient behaviors under dynamic driving cycle } \\
\text { Experimentally validated }\end{array}$ \\
Fleckenstein et al. [91] & $\begin{array}{c}\text { Three-dimensional } \\
\text { model + FVM }\end{array}$ & $\begin{array}{c}\text { Different current density and local SOC inhomogeneities at } \\
\text { different cell layers, MATLAB (MathWorks, MA, USA) simulation } \\
\text { and experimental validation }\end{array}$ \\
\hline
\end{tabular}

\subsection{Direct Impedance Measurement-Based Temperature Estimation}

Cell internal temperature estimation using a lumped-parameter thermal model and an approximate distributed thermal model have several drawbacks. Firstly, accurate determination of thermal model parameters such as heat generation and cell thermal properties is highly challenging. Heat generation inside the cell is typically approximated by measuring the cell operating current, voltage and the internal resistance that are again functions of $\mathrm{SOC}$, cell internal temperature and $\mathrm{SOH}$. Moreover, a cell is constructed using many different materials combined into a layered structure and thermal contact resistances between these layers are often unknown. Temperature estimation methods use surface temperature measurements and even the combination of surface-mounted temperature sensor and thermal model typically failed to detect the thermal runaway as rapid fluctuations in the internal temperature is difficult to capture using surface mounted sensors because the heat conduction between the core and battery surface takes a considerable amount of time [92]. Furthermore, embedding micro-temperature sensors within the cell $[93,94]$ is not practically possible for a large capacity LIB pack from a manufacturing complexity and system cost point of view. Hence, the core temperature measurement using a physical sensor is not an appropriate method for industrial applications.

Srinivasan et al. $[95,96]$ noticed that the phase of electrochemical impedance in the frequency range of 40 to $100 \mathrm{~Hz}$ is temperature-sensitive but insensitive to changes in other parameters such as $\mathrm{SOC}$ and $\mathrm{SOH}$. Based on these findings, they demonstrated an electrochemical impedance-based cell internal temperature estimation strategy. However, they assumed the uniform internal temperature and the estimation method is only valid in the temperature range of from -20 to $66^{\circ} \mathrm{C}$. The temperature estimation considering the effect of temperature non-uniformity on electrochemical impedance was studied by Schmidt et al. [97] based on the principle derived by Troxler et al. [98]. Both the strategy developed by Srinivasan et al. and Schmidt et al. were only able to estimate the mean temperature of the cell, however, in real-life application, especially in the case of cylindrical battery under high charging/discharging current, the difference between internal maximum temperature, surface temperature and mean temperature are significantly high. Therefore, Richardson et al. [3] further extended the research and developed a thermalimpedance model by combining an EIS measurement at a single frequency with a surface temperature measurement for precise determination of internal temperature distribution. The fundamental steps in direct impedance measurement-based temperature estimation as presented by Richardson et al. [3] is shown in Figure 4.

The approach of Richardson et al. does not require knowledge of cell thermal properties, heat generation or thermal boundary conditions, however, the major limitation is the online impedance determination of each cell which is highly challenging. Moreover, uncertainties of environmental factors were not considered and a surface-mounted temperature sensor needs to be installed on each cell which is impractical so far. Whilst few approaches of online determination of impedance spectra across multiple frequencies using onboard power electronics of EVs have been reported [99], the application of these strategies in real-time temperature estimation has not yet been investigated. Furthermore, interpreting impedance measurements under superimposed DC currents is yet to be systematically investigated. 


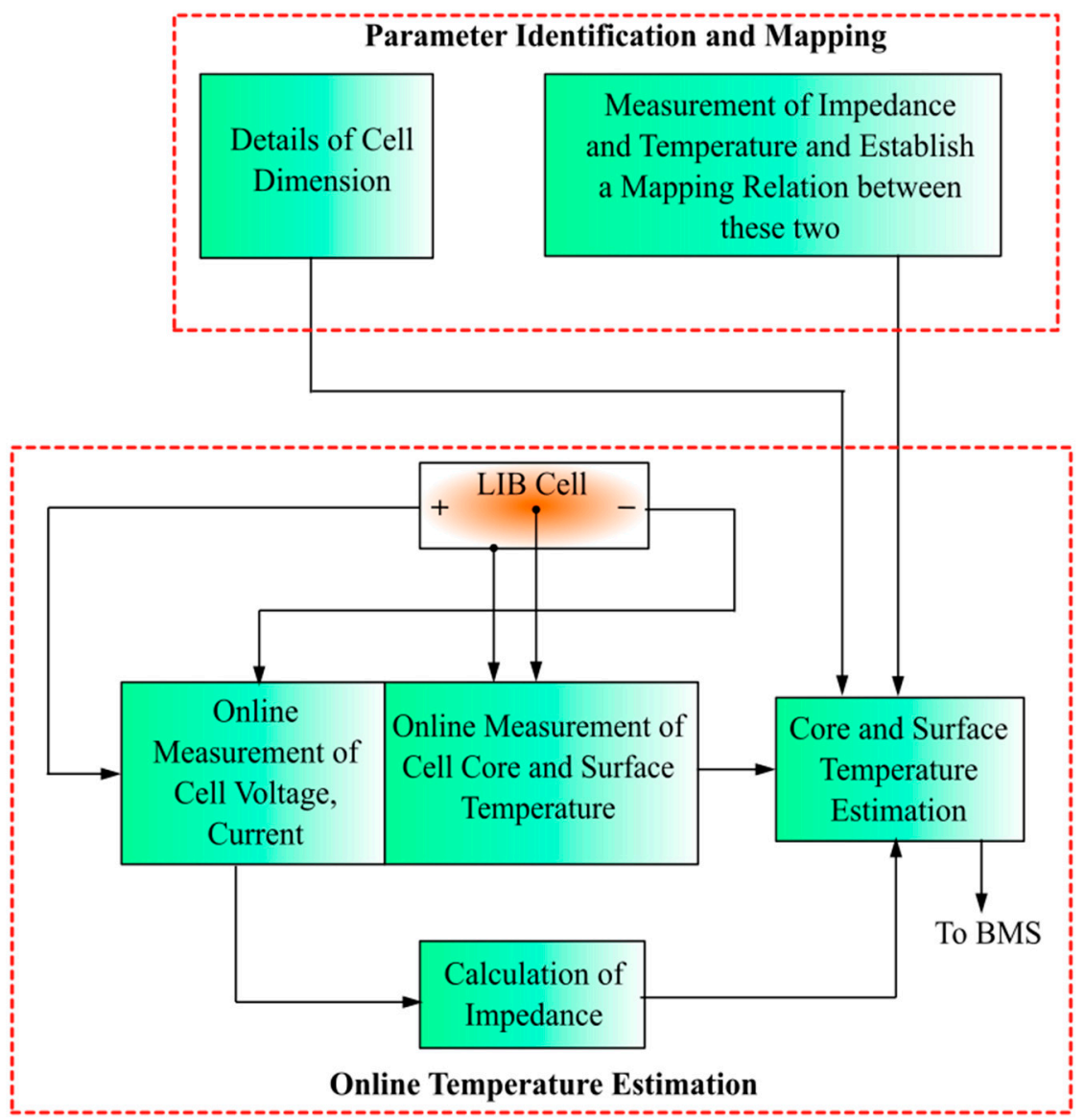

Figure 4. Fundamental steps in direct impedance measurement-based temperature estimation.

Online EIS-based temperature estimation strategy termed impedance-temperature detection (ITD) was proposed by Richardson and Howey [100] for sensorless temperature estimation which is adaptive to cell ageing and practical uncertainties. However, ITD cannot provide a general solution alone, thus, such a strategy combines surface-mounted sensors with ITD for accurate online temperature estimation [3]. Still, temperature sensors are required to be installed. Further to this study, they integrated ITD with an electricthermal model along with a DEKF for online core temperature estimation of a LIB cell even with unknown convection coefficient. They also demonstrated that the performance of the thermal model plus ITD is almost similar to the ITD with surface thermal sensors. Despite the advantages, the major limitations of the strategy are online impedance determination and the requirement of an accurate electric thermal model, thus encompassing the same drawback of conventional thermal modelling-based strategies. Moreover, although the strategy can estimate both core and surface temperature of an individual cell, the pack-level estimation strategy was not illustrated in this study.

The influence of cell temperature, SOC and SOH on the impedance spectrum, excitation frequency and thereby estimation accuracy of cell internal temperature was investigated by Zhu et al. [101]. Here, the temperature estimation was made based on an impedance response matrix analysis which was developed using EIS measurements. Despite high accuracy, the effect of the nonuniformity of the cell temperature and the correction method was not considered. Moreover, an extensive experimental study is required for modelling and the computational cost is also very high. Thus, the online application of the strategy is challenging. Identification of suitable frequency and other EIS parameters is very difficult whilst the estimation accuracy significantly depends on these parameters. Moreover, accurate determination of the real and imaginary parts of the impedance is highly challenging, whilst different decisions for these two parts leads to inaccurate tem- 
perature estimation. A combination of Linear Parameter Varying (LPV) thermal model and a polytopic observer-based battery-cell temperature estimation algorithm was proposed by Debert et al. [102]. The EIS-based strategy was also employed in references [3,103-106] to estimate the core temperature. Despite high accuracy, the major limitation is the determination of accurate impedance-temperature characteristics and it should be acquired in advance through tedious preliminary tests. In addition, the impedance-temperature characteristic of a cell is influenced by cell ageing leading to inaccurate prediction due to $\mathrm{SOH}$ deterioration. A summary of direct impedance measurement-based temperature estimation strategies is presented in Table 4.

Table 4. Summary of direct impedance measurement-based strategies.

\begin{tabular}{ccc}
\hline Reference & Types of Models & Important Note \\
\hline Srinivasan et al. [95,96] & $\begin{array}{c}\text { Direct measurement of } \\
\text { electrochemical impedance }\end{array}$ & Experimental validation with EIS data \\
Schmidt et al. [97] & $\begin{array}{c}\text { Direct measurement of } \\
\text { electrochemical impedance }\end{array}$ & $\begin{array}{c}\text { Temperature non-uniformity was not considered, } \\
\text { experimentally validated }\end{array}$ \\
\hline Richardson et al. [3] & $\begin{array}{c}\text { Thermal-impedance model + EIS } \\
\text { measurement at single frequency + } \\
\text { surface temperature feedback }\end{array}$ & $\begin{array}{c}\text { Independent of cell thermal properties, heat } \\
\text { generation or thermal boundary conditions, } \\
\text { experimental validation with EIS data }\end{array}$ \\
\hline Richardson and Howey [100] & $\begin{array}{c}\text { Online EIS measurement } \\
\text { (impedance-temperature detection (ITD) } \\
\text { + dual-extended Kalman filter (DEKF) }\end{array}$ & $\begin{array}{c}\text { Unknown convection coefficient is considered, } \\
\text { experimentally validated }\end{array}$ \\
\hline Zhu et al. [101] & $\begin{array}{c}\text { Impedance response matrix analysis, } \\
\text { developed using EIS measurements }\end{array}$ & $\begin{array}{c}\text { Influence of cell temperature, SOC and SOH on the } \\
\text { impedance spectrum, experimental validation with } \\
\text { EIS data }\end{array}$ \\
\hline
\end{tabular}

\subsection{Machine Learning-Based Temperature Estimation}

With the overwhelming complexity of the electrochemical reactions inside the battery and the sensitivity of the battery parameters to the uncertainties of the working environment, the thermodynamic behavior varies significantly from the center region to the surface region. Most of the existing distributed thermal models and the lumped parameter thermal models are incapable to consider the spatiotemporal distribution of LIB packs, especially in the case of large-capacity battery packs. Moreover, it is highly difficult to represent these spatiotemporal dynamics by a single physics-based model. Here, the machine learning (ML) algorithms were widely employed to preserve the local dynamics to improve the modelling accuracy of nonlinear systems such as LIB. A schematic layout of the ML-based temperature estimation scheme is shown in Figure 5.

Liu and Li [107] employed a hybrid model of EECM and neural network (NN)based learning approach to develop a spatiotemporal thermodynamic model of LIB for accurate estimation of internal temperature distribution. The data-driven NN model used commonly measured signals of BMS to compensate for the model-plant mismatch caused by spatial nonlinearity and other model uncertainties. NN and support vector machine (SVM)-based [108] LIB temperature estimation strategy was investigated by Sbarufatti et al. [109]. A hybrid model of an radial basis function neural network (RBFNN) and EKF was employed by Liu et al. [110] to estimate the internal temperature of LIB. While they have considered the impact of temperature on cell behavior, the primary intention of these models was the estimation of SOC or $\mathrm{SOH}$ rather than estimating the cell temperature. One of the major challenges of pure ML-based strategies is the generalization capability. Feng et al. [111] developed an effective electrochemical-thermal-neural-network (ETNN) by fusing a lumped parameter electrochemical thermal, feed-forward neural network (FFNN) and a UKF. This method demonstrated appreciable performance in predicting the state of temperature (SOT) in a wide temperature range and large current conditions. However, the modelling is highly complex, the accuracy over different charging current/drive cycles was 
not tested. Moreover, the computational efficiency and the suitability for online application are questionable. The back of the ETNN is the electrochemical model thus encompassing drawbacks similar to electrochemical models. In general, while ML-based schemes are computationally efficient, collecting training data and model training procedures are highly complex and time expensive. Moreover, real-life battery test data were not considered during ML-based model training in the existing literature; therefore, the accuracy of the existing ML-based strategies is still questionable. A summary of ML-based techniques reported by researchers is presented in Table 5 .

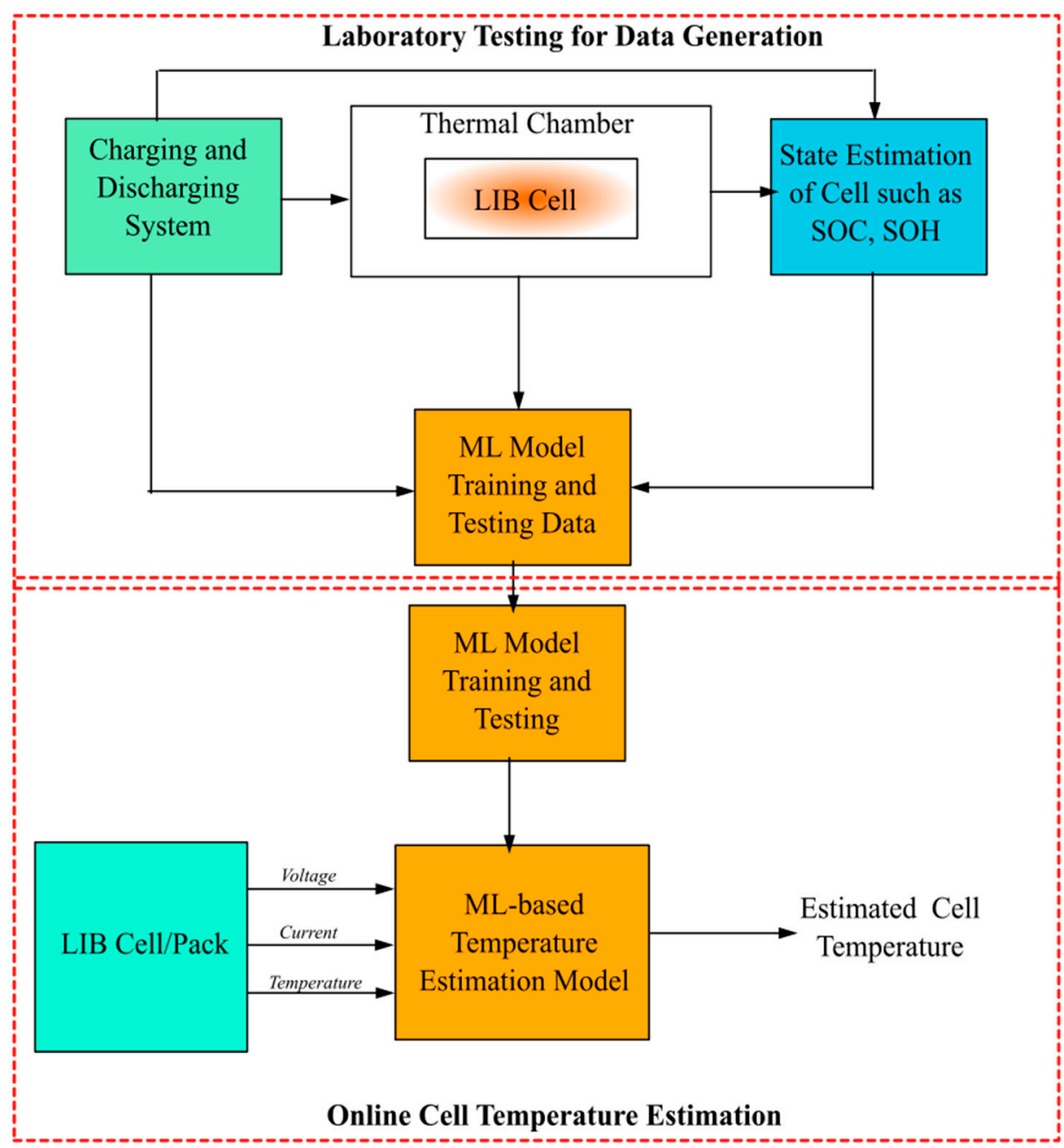

Figure 5. Schematic layout of ML-based temperature estimation scheme.

Table 5. Summary of ML-based temperature estimation techniques.

\begin{tabular}{ccc}
\hline Reference & Types of Models & Important Note \\
\hline Liu and Li [107] & $\begin{array}{c}\text { EECM + neural network } \\
\text { (NN)-based learning approach }\end{array}$ & $\begin{array}{c}\text { Model-plant mismatch caused by spatial nonlinearity and other } \\
\text { model uncertainties, NN-model was validated using } \\
\text { experimental data }\end{array}$ \\
\hline Sbarufatti et al. [109] & $\begin{array}{c}\text { Neural networks + Support } \\
\text { vector machines }\end{array}$ & $\begin{array}{c}\text { Influence of temperature, charging/discharging current, Python } \\
\text { (Python Software Foundation, Wilmington, DE, USA), NN and } \\
\text { SVM-model were validated using experimental data }\end{array}$ \\
\hline
\end{tabular}


Table 5. Cont

\begin{tabular}{ccc}
\hline Reference & Types of Models & Important Note \\
\hline Liu et al. [110] & $\begin{array}{c}\text { RBF neural network (RBNN) and } \\
\text { the extended Kalman filter (EKF) }\end{array}$ & $\begin{array}{c}\text { Impact of temperature on cell behavior, validated using } \\
\text { simulation data }\end{array}$ \\
Feng et al. [11] & $\begin{array}{c}\text { Electrochemical-thermal-neural- } \\
\text { network (ETNN) + Unscented } \\
\text { Kalman filter (UKF). }\end{array}$ & Wide temperature and large current conditions, Python, validated \\
using experimental data & \\
\hline
\end{tabular}

\subsection{Magnetic Nanoparticles-Based Temperature Estimation}

The magnetization of Magnetic Nanoparticles (MNPs) is nonlinear under an ac magnetic field and the accurate temperature of MNPs could be estimated by using the ratio of the third and fifth harmonic response [112-114]. Further, the temperature sensitivity of MNPs with the increased DC magnetic field was studied by Zhong et al. [115]. They found that the temperature sensitivity of MNPs will decrease with an increased DC magnetic field. Further to this study, Zou et al. [116] developed an improved Magnetic nanoparticles thermometer (MNPT) for the core temperature estimation of LIB which works based on the temperature measurement of magnetic nanoparticles (MNPs). They also suggested the optimal range of the DC magnetic field strength to ensure maximum temperature sensitivity and minimum temperature error of the MNPT. It is noticed that this type of estimation topology is very bulky and costly. Moreover, the suitability of online prediction has not yet been assessed.

\section{Discussion on Issues, Challenges and Future Research Recommendations}

Temperature estimation schemes for LIBs can be designed with different levels of complexity depending on the requirement of accuracy level and detailing of the prediction results. Detailed model results and more accurate predictions are essential for safer and reliable operation of BMS. However, integrating more detailed cell phenomena into the model eventually increases the modelling complexity, computational cost while, at the same time, reduces the suitability for online prediction and low-cost onboard BMS. For instance, modelling complexity increases if the temperature gradient of each cell layer is considered instead of concentrated heat generation at the core. Secondly, the heat fluxes inside and outside the battery can be considered in both axial and radial directions instead of considering only the radial direction for simplicity. Furthermore, detailed models typically consider different heat transport modes, that is, conduction, convective and radiation whereas simplified models consider only conduction heat transfer. Integrating a greater number of phenomena in thermal modelling requires a lot of parameters, resulting in additional requirements of experimental measurements, modelling time and solid domain knowledge. In addition, very detailed and accurate information of cell structure, material properties and cell assembly are also needed. However, collecting this information from the cell manufacturer is highly challenging due to the confidentiality of the design data. Therefore, it can be inferred from the above discussion that the detailed models could produce highly accurate and complete insight into cell thermodynamics, however, their computational complexity may not be suitable for online prediction and onboard low-cost BMS. In general, most of the estimation strategies require measurements from physical sensors, however, installing a physical sensor at each cell is not practically possible as a highcapacity LIB pack consists of thousands of individual cells. Moreover, installing a sensor at the cell core for core temperature measurement is highly challenging. Several estimation schemes estimate the core temperature based on the surface temperature measurement. However, it is very erroneous as it takes a significant amount of time for the heat to reach the surface from the core. So far, most of the research studies have covered the temperature estimation scheme of a single LIB cell. Temperature estimation of a LIB pack is much more challenging. Thus, significant further research is recommended here. Moreover, the influence of fast charging/discharging on the cell temperature has not yet been deeply 
explored. It is highly recommended to develop a health-conscious BMS. A summary of existing issues, challenges and future research recommendations to the research community are presented in Table 6.

Table 6. Summary of major issues, challenges and research recommendations.

\begin{tabular}{|c|c|}
\hline Strategy & Major Issues and Challenges \\
\hline $\begin{array}{l}\text { Electrochemical } \\
\text { Model-based }\end{array}$ & $\begin{array}{l}\text { Extremely detailed modelling is possible. Thus, it could } \\
\text { produce a highly accurate prediction, however with the } \\
\text { expenses of very high computational cost. Thus, unsuitable } \\
\text { for online prediction by onboard BMS } \\
\text { In-depth prior knowledge of LIB chemistry is a must besides } \\
\text { expertise in mathematical modelling, resulting in dependence } \\
\text { on domain experts } \\
\text { - } \quad \text { Extensive experiments are required to accumulate detailed } \\
\text { information on battery characteristics } \\
\text { Modelling is highly complex } \\
\text { Developing an adaptive estimation scheme is } \\
\text { highly challenging } \\
\text { Poor generalization capability }\end{array}$ \\
\hline
\end{tabular}

Future Research Recommendations

- $\quad$ Significant future research is recommended to reduce modelling complexity and computational cost

- So far, it can produce the best prediction results, thus could be extensively used for the validation of other types of models and data acquisition for data-driven models

- $\quad$ LIB chemistry is highly sensitive to temperature, battery health and other uncertainties, thus, further research on adaptive modelling is recommended

- $\quad$ Modelling complexity and

- Most extensively used so far due to adequate accuracy and easy implementation, however, modelling complexity and computational cost increase with the order of the model, number of temperature measurement points (nodes) and the parameter distribution

Equivalent Electric

Model-based Circuit (EECM)

- Accurate EECM parameters are very difficult to identify, especially online parameter estimation

- $\quad$ Parameter tuning using external measurement is challenging and time expensive

- Few researchers also used electrochemical analysis for parameter identification and determination which possesses similar difficulties to electrochemical-based strategies

- $\quad$ Predictions are highly influenced by measurement noises and often too many physical sensors are required

- Lower order models/simplified models are so far extensively used for online prediction with the compromise of accuracy and detailed insight

- Completely data-driven black-box strategy, that is, prediction depends on the external measurements only, thus, minimal or no requirement of any domain-specific knowledge, however, the major challenge is the accumulation of high-quality large volume of training data

- $\quad$ No requirement of iterative complex mathematical calculation, thus, computational cost is adequate for online application, however, computational cost increases with the high volume (high resolution) data and number of feature vectors to obtain a better insight

Machine Learning (ML)-based

- Accumulation of high-resolution data especially manufacturer data and fault data are highly challenging. These data are important for accurate and adaptive prediction

- Generalization is challenging

- Currently not used on onboard BMS due to high training time and complex algorithm development and computational time, whilst it is noticed that very few efforts have been made so far

- Often, external measurements by physical sensors are required as feedback for online parameter adjustment, thus still requires installation of physical sensors
Computational cost can be controlled by treading-off between accuracy requirement and detailing of the model

- $\quad$ Adaptive parameterization is challenging, however with the fusion of advanced algorithms such as ML-based techniques, adaptive strategies could be developed

- $\quad$ These models can generate highly accurate results at the laboratory, thus could be used to generate data and model validation of other strategies

- $\quad$ Fusion of this strategy with other strategies such as ML-based techniques could produce enhanced accuracy and computational performance

- Instead of traditional filters, more advanced adaptive filtering techniques could be embedded for better performance

- While it is comparatively easy to develop adaptive models, however, very few efforts have been made so far.

- Cell characteristics are highly influenced by temperature, ageing and other uncertainties, thus, further research on adaptive modelling is recommended

- Generalization is difficult, however, with the incorporation of advanced adaptive algorithms, it could be possible

- With proper design efforts, it could be used for online prediction and implemented in onboard BMS with low processing power

- Very promising technology could be used for a future generation of sensorless temperature estimation strategies. Very little effort has been provided so far, thus, further research is recommended 
Table 6. Cont.

\begin{tabular}{|c|c|c|}
\hline Strategy & Major Issues and Challenges & Future Research Recommendations \\
\hline Numerical Model-based & $\begin{array}{l}\text { - These strategies use FEA and FVA. FEA and FVA based } \\
\text { temperature estimation strategies are considered the most } \\
\text { accurate and most computationally expensive } \\
\text { Due to iterative complex mathematical calculation, its } \\
\text { computational cost is very high, thus not suitable for } \\
\text { online prediction }\end{array}$ & $\begin{array}{l}\text { - Significant research and development are } \\
\text { required to improve computational cost } \\
\text { to make this suitable for online } \\
\text { prediction. As it is most accurate, it could } \\
\text { be used for other model validation and } \\
\text { accurate data collection }\end{array}$ \\
\hline $\begin{array}{l}\text { Direct Impedance } \\
\text { Measurement-based }\end{array}$ & $\begin{array}{l}\text { - The influence of temperature on cell impedance is used for } \\
\text { internal temperature estimation. However, online direct } \\
\text { measurement of impedance using onboard power electronics } \\
\text { is highly challenging } \\
\text { Changes in cell impedance due to temperature variation is } \\
\text { small, thus, accurate determination of such small changes is } \\
\text { highly difficult } \\
\text { Existing schemes are very bulky } \\
\text { - Very few research efforts have so far provided, not yet } \\
\text { practically implemented }\end{array}$ & $\begin{array}{l}\text { Promising technology, thus, significant } \\
\text { further research and development is } \\
\text { recommended to reduce scheme size and } \\
\text { assess the practical applicability in } \\
\text { onboard BMS } \\
\text { Accuracy in real-world applications } \\
\text { needs to be judged } \\
\text { Further research into online impedance } \\
\text { determination using onboard electronics } \\
\text { is also recommended } \\
\text { The cost of existing solutions is very } \\
\text { high, which needs to be addressed }\end{array}$ \\
\hline $\begin{array}{l}\text { Magnetic } \\
\text { Nanoparticle-based }\end{array}$ & - Very new technology, it is too early to comment & $\begin{array}{l}\text { - Practical applicability in onboard } \\
\text { low-cost BMS has not yet been } \\
\text { investigated. Overall, significant further } \\
\text { research is required }\end{array}$ \\
\hline
\end{tabular}

\section{Conclusions}

This article presented a comprehensive review of the state-of-the-art temperature estimation strategies for lithium-ion batteries (LIBs) covering the necessity of an optimum estimation strategy, detailed discussion on the existing strategies, current issues, challenges and future research recommendations. It can be inferred that an accurate temperature estimation of LIBs is indispensable for effective thermal management, operational safety and several other crucial tasks of a Battery Management System (BMS). Measurement of each cell temperature using physical sensors is not practically possible, especially for a high-capacity battery pack consisting of thousands of individual cells. To develop an ideal temperature estimation scheme, one needs to concentrate on several factors, such as high accuracy, adaptability, small size, real-time estimation, distribution (to monitor the temperature gradient of the entire cell), low cost, and easily implementable for wide adoption. Typically, a temperature estimation scheme consists of a heat generation model and a heat transfer model. Depending on the modelling and computation strategies temperature estimation schemes can be grouped into six categories, namely, electrochemical model-based, equivalent electric circuit model (EECM)-based, machine learning (ML)-based, numerical analysis-based, direct impedance measurement-based, and magnetic nanoparticle-based. So far, numerical analysis-based schemes are most accurate followed by electro-chemical model-based schemes. However, both strategies have very high computational cost making them inappropriate for online prediction by a low-cost onboard BMS. Moreover, modelling complexity and experimental requirements are very high alongside the necessity of domain-specific knowledge. EECM-based schemes can be designed with different levels of complexity, accuracy level and computational cost. Simplified lower-order EECM-based schemes are extensively used in the literature and practice. Machine learning (ML)-based schemes are very promising due to their higher level of accuracy, ease of implementation and adaptability. In addition, reduced or even no requirement of equivalent modelling and domain experts. However, to obtain the feature vectors, very large volume and high-quality data are required which are typically very challenging to acquire. Here, a hybrid strategy combining an EECM and an ML is presumably a suitable solution. Direct impedance measurement and magnetic nanoparticle-based schemes are very newly developed. It is too early to assess their capability and suitability for online prediction and implementation in onboard BMS. Therefore, systematic guidelines about open research areas and future 
research directions are highlighted in this study. It is also noticed that the majority of the research studies proposed temperature estimation schemes of a single LIB cell whereas temperature estimation of a LIB pack is much more challenging. Thus, significant further research is recommended here a well.

Author Contributions: Conceptualization, S.S.W.; methodology, A.S. and S.S.W.; investigation, A.S.; resources, S.S.W.; writing-original draft preparation, A.S.; writing-review and editing, A.S. and S.S.W.; visualization, A.S.; supervision, S.S.W. All authors have read and agreed to the published version of the manuscript.

Funding: This research received no external funding.

Institutional Review Board Statement: Not applicable.

Informed Consent Statement: Not applicable.

Data Availability Statement: Not applicable.

Conflicts of Interest: The authors declare no conflict of interest.

\section{References}

1. Jilte, R.D.; Kumar, R.; Ma, L. Thermal performance of a novel confined flow Li-ion battery module. Appl. Therm. Eng. 2019, 146, 1-11. [CrossRef]

2. Yang, X.-H.; Tan, S.-C.; Liu, J. Thermal management of li-ion battery with liquid metal. Energy Convers. Manag. 2016, 117, 577-585. [CrossRef]

3. Richardson, R.R.; Ireland, P.T.; Howey, D. Battery internal temperature estimation by combined impedance and surface temperature measurement. J. Power Sources 2014, 265, 254-261. [CrossRef]

4. Wang, Y.-F.; Wu, J.-T. Performance improvement of thermal management system of lithium-ion battery module on purely electric AUVs. Appl. Therm. Eng. 2019, 146, 74-84. [CrossRef]

5. Surya, S.; Samanta, A.; Marcis, V.; Williamson, S.S. Smart core and surface temperature estimation techniques for health-conscious lithium-ion battery management systems: A model-to-model comparison. Preprints 2021, 1-21. [CrossRef]

6. Tanim, T.R.; Rahn, C.D.; Wang, C.-Y. State of charge estimation of a lithium ion cell based on a temperature dependent and electrolyte enhanced single particle model. Energy 2015, 80, 731-739. [CrossRef]

7. Farmann, A.; Sauer, D.U. A study on the dependency of the open-circuit voltage on temperature and actual aging state of lithium-ion batteries. J. Power Sources 2017, 347, 1-13. [CrossRef]

8. Zheng, F.; Jiang, J.; Sun, B.; Zhang, W.; Pecht, M. Temperature dependent power capability estimation of lithium-ion batteries for hybrid electric vehicles. Energy 2016, 113, 64-75. [CrossRef]

9. Samanta, A.; Chowdhuri, S. Active cell balancing of lithium-ion battery pack using dual dc-dc converter and auxiliary lead-acid battery. J. Energy Storage 2021, 33, 102109. [CrossRef]

10. Samanta, A.; Chowdhuri, S.; Williamson, S. Machine learning-based data-driven fault detection/diagnosis of lithium-ion battery: A critical review. Electronics 2021, 10, 1309. [CrossRef]

11. Zhang, S.; Xu, K.; Jow, T. The low temperature performance of li-ion batteries. J. Power Sources 2003, 115, 137-140. [CrossRef]

12. Mohan, S.; Kim, Y.; Stefanopoulou, A.G. Energy-conscious warm-up of li-ion cells from subzero temperatures. IEEE Trans. Ind. Electron. 2016, 63, 2954-2964. [CrossRef]

13. Surya, S.; Marcis, V.; Williamson, S. Core temperature estimation for a lithium ion 18650 cell. Energies 2020, 14, 87. [CrossRef]

14. Surya, S.; Mn, A. Effect of fast discharge of a battery on its core temperature. In Proceedings of the 2020 International Conference on Futuristic Technologies in Control Systems \& Renewable Energy (ICFCR), Kerala, India, 23-24 September 2020. [CrossRef]

15. Wei, Z.; Zhao, J.; He, H.; Ding, G.; Cui, H.; Liu, L. Future smart battery and management: Advanced sensing from external to embedded multi-dimensional measurement. J. Power Sources 2021, 489, 229462. [CrossRef]

16. Steinhorst, S.; Lukasiewycz, M.; Narayanaswamy, S.; Kauer, M.; Chakraborty, S. Smart cells for embedded battery management. In Proceedings of the 2014 IEEE International Conference on Cyber-Physical Systems, Networks, and Applications, Hong Kong, China, 25-26 August 2014.

17. Huang, X.; Sui, X.; Stroe, D.-I.; Teodorescu, R. A review of management architectures and balancing strategies in smart batteries. In Proceedings of the IECON 2019-45th Annual Conference of the IEEE Industrial Electronics Society, Lisbon, Portugal, 14-17 October 2019.

18. Fleming, J.; Amietszajew, T.; Charmet, J.; Roberts, A.J.; Greenwood, D.; Bhagat, R. The design and impact of In Situ and operando thermal sensing for smart energy storage. J. Energy Storage 2019, 22, 36-43. [CrossRef]

19. Pan, Y.-W.; Hua, Y.; Zhou, S.; He, R.; Zhang, Y.; Yang, S.; Liu, X.; Lian, Y.; Yan, X.; Wu, B. A computational multi-node electro-thermal model for large prismatic lithium-ion batteries. J. Power Sources 2020, 459, 228070. [CrossRef]

20. Bernardi, D.M.; Pawlikowski, E.M.; Newman, J. A general energy balance for battery systems. J. Electrochem. Soc. 1985, 132, 5-12. [CrossRef] 
21. Sun, F.; Xiong, R.; He, H.; Li, W.; Aussems, J.E.E. Model-based dynamic multi-parameter method for peak power estimation of lithium-ion batteries. Appl. Energy 2012, 96, 378-386. [CrossRef]

22. Lu, L.; Han, X.; Li, J.; Hua, J.; Ouyang, M. A review on the key issues for lithium-ion battery management in electric vehicles. J. Power Sources 2013, 226, 272-288. [CrossRef]

23. Ghalkhani, M.; Bahiraei, F.; Nazri, G.-A.; Saif, M. Electrochemical-thermal model of pouch-type lithium-ion batteries. Electrochim. Acta 2017, 247, 569-587. [CrossRef]

24. Yang, X.-G.; Leng, Y.; Zhang, G.; Ge, S.; Wang, C.-Y. Modeling of lithium plating induced aging of lithium-ion batteries: Transition from linear to nonlinear aging. J. Power Sources 2017, 360, 28-40. [CrossRef]

25. Chen, M.; Bai, F.; Song, W.; Lv, J.; Lin, S.; Feng, Z.; Li, Y.; Ding, Y. A multilayer electro-thermal model of pouch battery during normal discharge and internal short circuit process. Appl. Therm. Eng. 2017, 120, 506-516. [CrossRef]

26. Zhao, Y.; Diaz, L.B.; Patel, Y.; Zhang, T.; Offer, G.J. How to cool lithium ion batteries: Optimising cell design using a thermally coupled model. J. Electrochem. Soc. 2019, 166, A2849-A2859. [CrossRef]

27. Damay, N.; Forgez, C.; Bichat, M.-P.; Friedrich, G. Thermal modeling of large prismatic $\mathrm{LiFePO}_{4} /$ graphite battery. Coupled thermal and heat generation models for characterization and simulation. J. Power Sources 2017, 283, 37-45. [CrossRef]

28. Allafi, W.; Zhang, C.; Uddin, K.; Worwood, D.; Dinh, T.Q.; Ormeno, P.A.; Li, K.; Marco, J. A lumped thermal model of lithium-ion battery cells considering radiative heat transfer. Appl. Therm. Eng. 2018, 143, 472-481. [CrossRef]

29. Esmaeili, J.; Jannesari, H. Developing heat source term including heat generation at rest condition for lithium-ion battery pack by up scaling information from cell scale. Energy Convers. Manag. 2017, 139, 194-205. [CrossRef]

30. Arora, S.; Shen, W.; Kapoor, A. Neural network based computational model for estimation of heat generation in $\mathrm{LiFePO}_{4}$ pouch cells of different nominal capacities. Comput. Chem. Eng. 2017, 101, 81-94. [CrossRef]

31. Hu, X.; Liu, W.; Lin, X.; Xie, Y. A comparative study of control-oriented thermal models for cylindrical li-ion batteries. IEEE Trans. Transp. Electrif. 2019, 5, 1237-1253. [CrossRef]

32. Xie, Y.; Li, W.; Hu, X.; Zou, C.; Feng, F.; Tang, X. Novel mesoscale electrothermal modeling for lithium-ion batteries. IEEE Trans. Power Electron. 2019, 35, 2595-2614. [CrossRef]

33. Friesen, A.; Mönnighoff, X.; Börner, M.; Haetge, J.; Schappacher, F.M.; Winter, M. Influence of temperature on the aging behavior of 18650-type lithium ion cells: A comprehensive approach combining electrochemical characterization and post-mortem analysis. J. Power Sources 2017, 342, 88-97. [CrossRef]

34. Fan, Y.; Bao, Y.; Ling, C.; Chu, Y.; Tan, X.; Yang, S. Experimental study on the thermal management performance of air cooling for high energy density cylindrical lithium-ion batteries. Appl. Therm. Eng. 2019, 155, 96-109. [CrossRef]

35. Saw, L.H.; Poon, H.M.; Thiam, H.S.; Cai, Z.; Chong, W.T.; Pambudi, N.A.; King, Y.J. Novel thermal management system using mist cooling for lithium-ion battery packs. Appl. Energy 2018, 223, 146-158. [CrossRef]

36. Liu, B.; Yin, S.; Xu, J. Integrated computation model of lithium-ion battery subject to nail penetration. Appl. Energy 2016, 183, 278-289. [CrossRef]

37. Doyle, M.; Fuller, T.F.; Newman, J.S. Modeling of galvanostatic charge and discharge of the lithium/polymer/insertion cell. J. Electrochem. Soc. 1993, 140, 1526-1533. [CrossRef]

38. Xiao, Y.; Fahimi, B. State-space based multi-nodes thermal model for lithium-ion battery. In Proceedings of the 2014 IEEE Transportation Electrification Conference and Expo (ITEC), Beijing, China, 31 August 2014.

39. Tian, N.; Fang, H.; Wang, Y. 3-D Temperature field reconstruction for a lithium-ion battery pack: A distributed kalman filtering approach. IEEE Trans. Control. Syst. Technol. 2019, 27, 847-854. [CrossRef]

40. Ruan, H.; Jiang, J.; Sun, B.; Gao, W.; Wang, L.; Zhang, W. Online estimation of thermal parameters based on a reduced wide-temperature-range electro-thermal coupled model for lithium-ion batteries. J. Power Sources 2018, 396, 715-724. [CrossRef]

41. Gu, W.B.; Wang, C.Y. Thermal-electrochemical modeling of battery systems. J. Electrochem. Soc. 2000, 147, 2910-2922. [CrossRef]

42. Kumaresan, K.; Sikha, G.; White, R.E. Thermal model for a li-ion cell. J. Electrochem. Soc. 2008, 155, A164-A171. [CrossRef]

43. Forgez, C.; Do, D.V.; Friedrich, G.; Morcrette, M.; Delacourt, C. Thermal modeling of a cylindrical LiFePO 4 /graphite lithium-ion battery. J. Power Sources 2010, 195, 2961-2968. [CrossRef]

44. Dees, D.W.; Battaglia, V.S.; Bélanger, A. Electrochemical modeling of lithium polymer batteries. J. Power Sources 2002, 110, 310-320. [CrossRef]

45. Lin, X.; Perez, H.E.; Siegel, J.; Stefanopoulou, A.G.; Li, Y.; Anderson, R.D.; Ding, Y.; Castanier, M. Online parameterization of lumped thermal dynamics in cylindrical lithium ion batteries for core temperature estimation and health monitoring. IEEE Trans. Control Syst. Technol. 2012, 21, 1745-1755. [CrossRef]

46. Choi, J.W.; Aurbach, D. Promise and reality of post-lithium-ion batteries with high energy densities. Nat. Rev. Mater. 2016, 1, 16013. [CrossRef]

47. Yang, F.; Wang, D.; Zhao, Y.; Tsui, K.-L.; Bae, S.J. A study of the relationship between coulombic efficiency and capacity degradation of commercial lithium-ion batteries. Energy 2018, 145, 486-495. [CrossRef]

48. Wang, Q.; Zhao, X.; Ye, J.; Sun, Q.; Ping, P.; Sun, J. Thermal response of lithium-ion battery during charging and discharging under adiabatic conditions. J. Therm. Anal. Calorim. 2016, 124, 417-428. [CrossRef]

49. Chen, Y. Heat transfer phenomena in lithium/polymer-electrolyte batteries for electric vehicle application. J. Electrochem. Soc. 1993, 140, 1833-1838. [CrossRef] 
50. Fuller, T.F.; Doyle, M.; Newman, J. Relaxation phenomena in lithium-ion-insertion cells. J. Electrochem. Soc. 1994, 141, 982-990. [CrossRef]

51. Pals, C.R.; Newman, J. Thermal modeling of the lithium/polymer battery: I discharge behavior of a single cell. J. Electrochem. Soc. 1995, 142, 3274-3281. [CrossRef]

52. Pals, C.R.; Newman, J. Thermal modeling of the lithium/polymer battery: II temperature profiles in a cell stack. J. Electrochem. Soc. 1995, 142, 3282-3288. [CrossRef]

53. Al Hallaj, S.; Maleki, H.; Hong, J.; Selman, J. Thermal modeling and design considerations of lithium-ion batteries. J. Power Sources 1999, 83, 1-8. [CrossRef]

54. Gomadam, P.M.; White, R.E.; Weidner, J.W. Modeling heat conduction in spiral geometries. J. Electrochem. Soc. 2003, 150, A1339-A1345. [CrossRef]

55. Chen, Y.; Evans, J.W. Three-dimensional thermal modeling of lithium-polymer batteries under galvanostatic discharge and dynamic power profile. J. Electrochem. Soc. 1994, 141, 2947-2955. [CrossRef]

56. Newman, J.; Tiedemann, W. Temperature rise in a battery module with constant heat generation. J. Electrochem. Soc. 1995, 142, 1054-1057. [CrossRef]

57. Chen, Y.; Evans, J.W. Thermal analysis of lithium-ion batteries. J. Electrochem. Soc. 1996, 143, 2708-2712. [CrossRef]

58. Rao, L.; Newman, J. Heat-generation rate and general energy balance for insertion battery systems. J. Electrochem. Soc. 1997, 144, 2697-2704. [CrossRef]

59. Kim, G.-H.; Pesaran, A.; Spotnitz, R. A three-dimensional thermal abuse model for lithium-ion cells. J. Power Sources 2007, 170, 476-489. [CrossRef]

60. Thomas, K.E.; Newman, J.; Darling, R.M. Mathematical modeling of lithium batteries. In Advances in Lithium-Ion Batteries; Springer: Berlin/Heidelberg, Germany, 2002; pp. 345-392.

61. Van Schalkwijk, W.; Scrosati, B. Advances in lithium ion batteries introduction. In Advances in Lithium-Ion Batteries; Springer: Berlin/Heidelberg, Germany, 2002.

62. Smith, K.; Wang, C.-Y. Power and thermal characterization of a lithium-ion battery pack for hybrid-electric vehicles. J. Power Sources 2006, 160, 662-673. [CrossRef]

63. Khateeb, S.A.; Amiruddin, S.; Farid, M.; Selman, J.R.; Al-Hallaj, S. Thermal management of li-ion battery with phase change material for electric scooters: Experimental validation. J. Power Sources 2005, 142, 345-353. [CrossRef]

64. Fang, W.; Kwon, O.J.; Wang, C.-Y. Electrochemical-thermal modeling of automotive li-ion batteries and experimental validation using a three-electrode cell. Int. J. Energy Res. 2009, 34, 107-115. [CrossRef]

65. Kim, U.S.; Yi, J.; Shin, C.B.; Han, T.; Park, S. Modelling the thermal behaviour of a lithium-ion battery during charge. J. Power Sources 2011, 196, 5115-5121. [CrossRef]

66. Gerver, R.E.; Meyers, J.P. Three-dimensional modeling of electrochemical performance and heat generation of lithium-ion batteries in tabbed planar configurations. J. Electrochem. Soc. 2011, 158, A835-A843. [CrossRef]

67. Zhang, J.; Yang, X.-G.; Sun, F.; Wang, Z.; Wang, C.-Y. An online heat generation estimation method for lithium-ion batteries using dual-temperature measurements. Appl. Energy 2020, 272, 115262. [CrossRef]

68. Wang, P.; Yang, L.; Wang, H.; Tartakovsky, D.; Onori, S. Temperature estimation from current and voltage measurements in lithium-ion battery systems. J. Energy Storage 2021, 34, 102133. [CrossRef]

69. Marelli, S.; Corno, M. Model-based estimation of lithium concentrations and temperature in batteries using soft-constrained dual unscented kalman filtering. IEEE Trans. Control. Syst. Technol. 2021, 29, 926-933. [CrossRef]

70. Mahamud, R.; Park, C. Reciprocating air flow for li-ion battery thermal management to improve temperature uniformity. J. Power Sources 2011, 196, 5685-5696. [CrossRef]

71. Park, C.; Jaura, A.K. Dynamic Thermal Model of Li-Ion Battery for Predictive Behavior in Hybrid and Fuel Cell Vehicles; SAE Technical Paper Series; SAE International: Warrendale, PA, USA, 2003.

72. Chen, L.; Hu, M.; Cao, K.; Li, S.; Su, Z.; Jin, G.; Fu, C. Core temperature estimation based on electro-thermal model of lithium-ion batteries. Int. J. Energy Res. 2020, 44, 5320-5333. [CrossRef]

73. Maleki, H.; Shamsuri, A.K. Thermal analysis and modeling of a notebook computer battery. J. Power Sources 2003, 115, 131-136. [CrossRef]

74. Lin, X.; Perez, H.E.; Mohan, S.; Siegel, J.; Stefanopoulou, A.G.; Ding, Y.; Castanier, M.P. A lumped-parameter electro-thermal model for cylindrical batteries. J. Power Sources 2014, 257, 1-11. [CrossRef]

75. Li, D.; Yang, L. Identification of spatial temperature gradient in large format lithium battery using a multilayer thermal model. Int. J. Energy Res. 2019, 44, 282-297. [CrossRef]

76. Lin, X.; Stefanopoulou, A.G.; Perez, H.E.; Siegel, J.B.; Li, Y.; Anderson, R.D. Quadruple adaptive observer of the core temperature in cylindrical li-ion batteries and their health monitoring. In Proceedings of the 2012 American Control Conference (ACC), Montreal, QC, Canada, 27-29 June 2012. [CrossRef]

77. Lin, X.; Fu, H.; Perez, H.E.; Siege, J.B.; Stefanopoulou, A.G.; Ding, Y.; Castanier, M.P. Parameterization and observability analysis of scalable battery clusters for onboard thermal management. Oil Gas Sci. Technol. 2013, 68, 165-178. [CrossRef]

78. Sun, J.; Wei, G.; Pei, L.; Lu, R.; Song, K.; Wu, C.; Zhu, C. Online internal temperature estimation for lithium-ion batteries based on kalman filter. Energies 2015, 8, 4400-4415. [CrossRef] 
79. Dai, H.; Zhu, L.; Zhu, J.; Wei, X.; Sun, Z. Adaptive kalman filtering based internal temperature estimation with an equivalent electrical network thermal model for hard-cased batteries. J. Power Sources 2015, 293, 351-365. [CrossRef]

80. Doughty, D.H.; Butler, P.C.; Jungst, R.G.; Roth, E. Lithium battery thermal models. J. Power Sources 2002, 110, 357-363. [CrossRef]

81. Xie, Y.; Li, W.; Hu, X.; Lin, X.; Zhang, Y.; Dan, D.; Feng, F.; Liu, B.; Li, K. An enhanced online temperature estimation for lithium-ion batteries. IEEE Trans. Transp. Electrif. 2020, 6, 375-390. [CrossRef]

82. Sun, L.; Sun, W.; You, F. Core temperature modelling and monitoring of lithium-ion battery in the presence of sensor bias. Appl. Energy 2020, 271, 115243. [CrossRef]

83. Zhu, C.; Shang, Y.; Lu, F.; Jiang, Y.; Cheng, C.; Mi, C. Core temperature estimation for self-heating automotive lithium-ion batteries in cold climates. IEEE Trans. Ind. Inform. 2019, 16, 3366-3375. [CrossRef]

84. Xiao, Y. Model-based virtual thermal sensors for lithium-ion battery in EV applications. IEEE Trans. Ind. Electron. 2014, 62, 3112-3122. [CrossRef]

85. Ma, Y.; Cui, Y.; Mou, H.; Gao, J.; Chen, H. Core temperature estimation of lithium-ion battery for EVs using kalman filter. Appl. Therm. Eng. 2020, 168, 114816. [CrossRef]

86. Ismail, N.H.F.; Toha, S.F.; Azubir, N.A.M.; Ishak, N.H.M.; Hassan, I.D.M.K.; Ibrahim, B.S.K. Simplified heat generation model for lithium ion battery used in electric vehicle. IOP Conf. Ser. Mater. Sci. Eng. 2013, 53, 012014. [CrossRef]

87. Jeon, D.H. Numerical modeling of lithium ion battery for predicting thermal behavior in a cylindrical cell. Curr. Appl. Phys. 2014, 14, 196-205. [CrossRef]

88. Baba, N.; Yoshida, H.; Nagaoka, M.; Okuda, C.; Kawauchi, S. Numerical simulation of thermal behavior of lithium-ion secondary batteries using the enhanced single particle model. J. Power Sources 2014, 252, 214-228. [CrossRef]

89. Du, S.; Jia, M.; Cheng, Y.; Tang, Y.; Zhang, H.; Ai, L.; Zhang, K.; Lai, Y. Study on the thermal behaviors of power lithium iron phosphate (LFP) aluminum-laminated battery with different tab configurations. Int. J. Therm. Sci. 2015, 89, 327-336. [CrossRef]

90. Yi, J.; Lee, J.; Shin, C.B.; Han, T.; Park, S. Modeling of the transient behaviors of a lithium-ion battery during dynamic cycling. J. Power Sources 2015, 277, 379-386. [CrossRef]

91. Fleckenstein, M.; Bohlen, O.; Roscher, M.A.; Bäker, B. Current density and state of charge inhomogeneities in li-ion battery cells with $\mathrm{LiFePO}_{4}$ as cathode material due to temperature gradients. J. Power Sources 2011, 196, 4769-4778. [CrossRef]

92. Santhanagopalan, S.; Ramadass, P.; Zhang, J.Z. Analysis of internal short-circuit in a lithium ion cell. J. Power Sources 2009, 194, 550-557. [CrossRef]

93. Li, Z.; Zhang, J.; Wu, B.; Huang, J.; Nie, Z.; Sun, Y.; An, F.; Wu, N. Examining temporal and spatial variations of internal temperature in large-format laminated battery with embedded thermocouples. J. Power Sources 2013, 241, 536-553. [CrossRef]

94. Mutyala, M.S.K.; Zhao, J.; Li, J.; Pan, H.; Yuan, C.; Li, X. In Situ temperature measurement in lithium ion battery by transferable flexible thin film thermocouples. J. Power Sources 2014, 260, 43-49. [CrossRef]

95. Srinivasan, R.; Carkhuff, B.G.; Butler, M.H.; Baisden, A.C. Instantaneous measurement of the internal temperature in lithium-ion rechargeable cells. Electrochim. Acta 2011, 56, 6198-6204. [CrossRef]

96. Srinivasan, R. Monitoring dynamic thermal behavior of the carbon anode in a lithium-ion cell using a four-probe technique. J. Power Sources 2012, 198, 351-358. [CrossRef]

97. Schmidt, J.P.; Arnold, S.; Loges, A.; Werner, D.; Wetzel, T.; Ivers-Tiffée, E. Measurement of the internal cell temperature via. impedance: Evaluation and application of a new method. J. Power Sources 2013, 243, 110-117. [CrossRef]

98. Troxler, Y.; Wu, B.; Marinescu, M.; Yufit, V.; Patel, Y.; Marquis, A.J.; Brandon, N.P.; Offer, G. The effect of thermal gradients on the performance of lithium-ion batteries. J. Power Sources 2014, 247, 1018-1025. [CrossRef]

99. Brandon, N.; Mitcheson, P.; Yufit, V.; Howey, D.; Offer, G. Battery Monitoring in Electric Vehicles, Hybrid Electric Vehicles and Other Applications. U.S. Patent 2,013,022,915,6A1, 8 May 2013.

100. Richardson, R.R.; Howey, D.A. Sensorless battery internal temperature estimation using a kalman filter with impedance measurement. IEEE Trans. Sustain. Energy 2015, 6, 1190-1199. [CrossRef]

101. Zhu, J.; Sun, Z.; Wei, X.; Dai, H. A new lithium-ion battery internal temperature on-line estimate method based on electrochemical impedance spectroscopy measurement. J. Power Sources 2015, 274, 990-1004. [CrossRef]

102. Debert, M.; Colin, G.; Bloch, G.; Chamaillard, Y. An observer looks at the cell temperature in automotive battery packs. Control Eng. Pract. 2013, 21, 1035-1042. [CrossRef]

103. Hu, X.; Yuan, H.; Zou, C.; Li, Z.; Zhang, L. Co-estimation of state of charge and state of health for lithium-ion batteries based on fractional-order calculus. IEEE Trans. Veh. Technol. 2018, 67, 10319-10329. [CrossRef]

104. Wang, Z.; Ma, J.; Zhang, L. State-of-health estimation for lithium-ion batteries based on the multi-island genetic algorithm and the gaussian process regression. IEEE Access 2017, 5, 21286-21295. [CrossRef]

105. Hande, A. Internal battery temperature estimation using series battery resistance measurements during cold temperatures. J. Power Sources 2006, 158, 1039-1046. [CrossRef]

106. Howey, D.; Mitcheson, P.D.; Yufit, V.; Offer, G.; Brandon, N.P. Online measurement of battery impedance using motor controller excitation. IEEE Trans. Veh. Technol. 2014, 63, 2557-2566. [CrossRef]

107. Liu, Z.; Li, H. A Spatiotemporal estimation method for temperature distribution in lithium-ion batteries. IEEE Trans. Ind. Inform. 2014, 10, 2300-2307. [CrossRef]

108. Khelif, R.; Chebel-Morello, B.; Malinowski, S.; Laajili, E.; Fnaiech, F.; Zerhouni, N. Direct remaining useful life estimation based on support vector regression. IEEE Trans. Ind. Electron. 2017, 64, 2276-2285. [CrossRef] 
109. Sbarufatti, C.; Corbetta, M.; Giglio, M.; Cadini, F. Adaptive prognosis of lithium-ion batteries based on the combination of particle filters and radial basis function neural networks. J. Power Sources 2017, 344, 128-140. [CrossRef]

110. Liu, K.; Li, K.; Peng, Q.; Guo, Y.; Zhang, L. Data-driven hybrid internal temperature estimation approach for battery thermal management. Complexity 2018, 2018, 1-15. [CrossRef]

111. Feng, F.; Teng, S.; Liu, K.; Xie, J.; Xie, Y.; Liu, B.; Li, K. Co-estimation of lithium-ion battery state of charge and state of temperature based on a hybrid electrochemical-thermal-neural-network model. J. Power Sources 2020, 455, 227935. [CrossRef]

112. Li, Y.; Liu, W.; Zhong, J. Comparison of noninvasive and remote temperature estimation employing magnetic nanoparticles in DC and AC applied fields. In Proceedings of the 2012 IEEE International Instrumentation and Measurement Technology Conference, Graz, Austria, 13-16 May 2012.

113. Zhong, J.; Dieckhoff, J.; Schilling, M.; Ludwig, F. Influence of static magnetic field strength on the temperature resolution of a magnetic nanoparticle thermometer. J. Appl. Phys. 2016, 120, 143902. [CrossRef]

114. Yoshida, T.; Enpuku, K. Simulation and quantitative clarification of ac susceptibility of magnetic fluid in nonlinear brownian relaxation region. Jpn. J. Appl. Phys. 2009, 48, 127002. [CrossRef]

115. Zhong, J.; Liu, W.; Du, Z.; De Morais, P.C.; Xiang, Q.; Xie, Q. A noninvasive, remote and precise method for temperature and concentration estimation using magnetic nanoparticles. Nanotechnology 2012, 23, 075703. [CrossRef]

116. Zou, D.; Li, M.; Wang, D.; Li, N.; Su, R.; Zhang, P.; Gan, Y.; Cheng, J. Temperature estimation of lithium-ion battery based on an improved magnetic nanoparticle thermometer. IEEE Access 2020, 8, 135491-135498. [CrossRef] 